$\mathcal{G}_{\text {https://doi.org/10.3765/sp.13.3 }}^{\text {Semantics \& Pragmatics Volume 13, Article 3: 1-57, } 2020}$

\title{
Numerals and the theory of number*
}

\author{
Luisa Martí \\ Queen Mary University of London
}

Submitted 2018-07-19 / First decision 2018-11-19 / Revision received 2019-05-09 / Second decision 2019-10-15 / Revision received 2020-01-10 / Accepted 2020-02-01 / Published 2020-04-09 / Final typesetting 2022-05-03

\begin{abstract}
I develop an account of the semantics and nominal number marking of the numeral+noun construction in Turkish, Western Armenian and English that combines insights from Scontras's (2014) approach to the same data with Martí's $(2017,2020)$ treatment of grammatical number, based on Harbour 2014. Fundamental to my approach are two of Harbour's number features, [ \pm atomic] and $[ \pm$ minimal], their compositional semantics, and a syntax where these features take the phrase that contains the numeral, which I call NumeralP, as their sister, following Scontras. The morphological number marking we find on noun phrases with numerals across languages is thus viewed as a result of the principled interplay of the spell out of number features, their place, and that of numerals, in the syntactic structure of noun phrases, and their semantic import. Numerals are provided with a uniform semantics, no matter the language, and the semantics assumed for Turkish and Western Armenian noun phrases is empirically justified. I compare my proposal to Scontras 2014 and to Bale, Gagnon \& Khanjian 2011a, highlighting in particular the empirical and theoretical shortcomings of the latter. The proposed account fully grounds the semantic notions of minimality and atomicity in the morpho-syntax, uncovers a new domain where the effects of [ \pm minimal] may be detected (cf. Harbour 2011, 2016), and demonstrates that an inclusive-only approach to plurality is not necessary in the account of the data.
\end{abstract}

Keywords: numerals, grammatical number, nouns, features, semantics

* Many thanks to Klaus Abels, Elias Boike, Gabi Danon, Hossep Dolatian, Emrah Görgülü, Nihan Ketrez, Hrayr Khanjian, Balkız Öztürk, Cilene Rodrigues, Greg Scontras, Nilüfer Şener, Michele Sigler, Kriszta Szendrői, Bert Vaux and several anonymous reviewers for very helpful criticism, judgments, discussion and/or support.

(C)2020 Luisa Martí

This is an open-access article distributed under the terms of a Creative Commons Attribution License (https://creativecommons.org/licenses/by/3.o/). 
Luisa Martí

\section{Introduction}

This paper is concerned with the morphology and compositional semantics of the numeral ${ }^{1}+$ noun construction in plural-marking languages. At least three types of languages must be recognized, depending on the morphological shape of the noun accompanying the numeral. In the first type of language, exemplified by English, Spanish or German, the numeral one obligatorily appears with morphologically singular nouns, and any numeral greater than one, with morphologically plural nouns: ${ }^{2}$

\section{(1) One $\{$ boy $\mid$ *boys $\}$ \\ (2) Two/three...etc. \{boys | *boy\}}

In the second type, exemplified by Turkish (Bale, Gagnon \& Khanjian 2011a), Finnish (Nelson \& Toivonen 2000), or Hungarian (Farkas \& de Swart 2010), all numerals combine with morphologically singular nouns, even numerals greater than one, even though these languages do have the means of marking plurality on nouns: $:^{3,4,5}$

(3) Turkish
Bir \{çocuk | *çocuk-lar\}
one boy.SG boy-PL
'One boy'
(4) Turkish
Iki \{çocuk | *çocuk-lar\}
two boy.SG boy-PL
'Two boys'

1 By numeral, in this paper I mean 'cardinal numeral'.

2 Actually, a more accurate description, as discussed for example in Krifka 1989 and Borer 2005, is that numerals other than morphologically singular one in English combine with morphologically plural nouns: *zero boy vs. zero boys, 1.0 boys vs. *1.o boy. I put aside these cases in what follows.

3 Abbreviations in glosses are as follows: 1 = first person; $2=$ second person; $3=$ third person; $\mathrm{ABL}=$ ablative case; ABSOLUTIVE = absolutive case; $\mathrm{ACC}=$ accusative case; $\mathrm{AOR}=$ aorist; DAT = dative case; CLASS = classifier; DEF = definite determiner; ERG = ergative case; EVID = evidential; GEN = genitive case; $\mathrm{HAB}=$ habitual; IMP = imperfective; INDIC = indicative; LOC $=$ locative case; $\mathrm{NEG}=$ negation; $\mathrm{NOM}=$ nominative case; PASs $=$ passive PAST $=$ past tense; $\mathrm{PL}=$ plural; $\mathrm{PRES}=$ present; $\mathrm{PROG}=$ progressive; $\mathrm{SG}=$ singular.

4 The plural marker in Turkish is the suffix -lAr, subject to vowel harmony (see Kornfilt 1997: p. 268). In Hungarian, it is the suffix $-(V) k$ (see Farkas \& de Swart 2003).

5 Emrah Görgülü, Nihan Ketrez, Balkız Öztürk and Nilüfer Şener helped with the Turkish data. 
In the third type, exemplified by Western Armenian (Bale, Gagnon \& Khanjian 2011a, Donabédian 1993, Sigler 1997) or Miya (for its inanimate nouns, as discussed in Schuh 1989, 1998), plural marking on the noun is optional for numerals greater than one: 6,7

(5) Western Armenian

Meg \{dəgha | *dəgha-ner

one boy.sG boy-PL

'One boy'

(6) Western Armenian

Yergu \{dəgha | dəgha-ner\}

two boy.SG boy-PL

'Two boys'

These patterns are summarized in Table $1:{ }^{8}$

\begin{tabular}{llll}
\hline & Type 1 & Type 2 & Type 3 \\
\hline $\begin{array}{l}\text { One } N \\
\text { Two, etc. } N\end{array}$ & singular N & singular N & $\begin{array}{l}\text { singular N } \\
\text { singular or plural N }\end{array}$ \\
Languages & $\begin{array}{l}\text { English, Spanish, } \\
\text { German }\end{array}$ & $\begin{array}{l}\text { Hungarian, }{ }^{9} \\
\text { Turkish, Finnish }\end{array}$ & $\begin{array}{l}\text { Western Armenian, } \\
\text { Miya }\end{array}$
\end{tabular}

Table 1 The three language types

Bale, Gagnon \& Khanjian (2011a) argue for an account of these patterns where the semantics of both numerals and nouns may vary from one language type to another. On the other hand, Scontras (2014) assumes a single

6 The most productive strategy for pluralization in Miya adds $-a-C$ - $a w$ to the noun, where $C$ is the final consonant of the noun stem. The plural marker in Western Armenian is the suffix -(n)er. For semantic differences between the two versions of (6), see footnote 35.

7 Hossep Dolatian, Hrayr Khanjian, Michele Sigler and Bert Vaux helped with the Western Armenian data.

8 Languages that have no inflectional plural marking to begin with, such as Japanese (cf. Nakanishi \& Tomioka 2004), are not part of the current study. More complex patterns are attested in other languages (see, e.g., Corbett 2000: pp. 210-6 and Franks 1995 on Slavic languages, Mittendorf \& Sadler 2005 and Sadler 2000 on Welsh). I also do not consider pluralized numerals (see Danon 2012 and references cited there), or complex numerals (see Ionin \& Matushansky 2006, 2018) in this paper.

9 Kriszta Szendrói helped with the Hungarian data. 
semantics for all numerals (including one) and a single semantics for morphologically singular noun phrases - in his account, the observed variation results from a different semantics for the feature [SINGULAR] in different languages. ${ }^{10}$

I show in this paper that the assumptions Bale, Gagnon \& Khanjian (2011a) make concerning the semantics of morphologically singular noun phrases in Turkish and Western Armenian are empirically flawed (cf. Martí 2017, Sağ 2016, 2017), a problem that does not arise for Scontras. Scontras's treatment is superior also in that he assumes a uniform semantics for numerals throughout.

However, Scontras's explanation relies on the stipulative claim that languages of types 2 and 3 use a singular feature that is sensitive to elements without minimal parts in a certain domain, which may or may not be atoms. I improve Scontras's account by appealing to Harbour's $(2011,2014)$ theory of grammatical number, where the source of sensitivity to minimal parts is the feature [ \pm minimal], different from [ \pm atomic]. [ \pm Minimal] is involved, according to Harbour, in the generation of a series of number distinctions across languages and its use goes well beyond the role I propose for it in the numeral+noun construction; thus, it is independently motivated. Hence, the compositional semantics of the number features that are needed for Scontras's explanation to work does not need to be stipulated in my analysis.

Embedding Scontras's account within Harbour's theory, however, cannot be done without changing Scontras's assumptions about plurality. Scontras builds his account on Sauerland 2003, where singular features are semantically contentful but plural features are semantically empty. Martí (2017, 2020), however, demonstrates that this approach to plurality is not compatible with Harbour's theory, but that an alternative, ambiguity account is. My proposal has, therefore, three key ingredients: Martí's account of plurality, Harbour's features, and Scontras's idea about the interaction between the semantics of number features and numerals. With these ingredients, I derive the variation in Table 1 on principled grounds. I demonstrate that neither

10 A third type of account of the contrast between type 1 and type 2 languages can be found in Farkas \& de Swart 2010. Theirs is an optimality-theoretic account that I don't discuss in the text, since I'm interested in demonstrating that a compositional semantics account works for the data at hand. Note that a different part of Farkas and de Swart's (2010) analysis, regarding the distribution of exclusive and inclusive plurality, is compatible with the account in Section 2.2. See Martí 2020 for more on this issue. 
presuppositions nor semantically vacuous plurals are necessary in the account of the data.

Like its predecessors, the syntactic and semantic account proposed here can be viewed as an alternative to accounts that take the variation in Table 1 to be the result of a special morpho-syntactic relationship (agreement/ concord) between numerals and nouns. The morphological shape of the noun in this construction is often thought of as a matter of agreement or concord between the noun and the numeral (see, e.g., Alexiadou 2019). Here, however, I show that resources used independently by Harbour to account for a vast array of empirical generalizations concerning the cross-linguistic typology of number systems can also be used to account for the semantics and the morphological realization of the noun of numeral+noun construction. Because of this, the theoretical cost of the analytical tools used here is small. What the account proposed below does is to ground the semantic notions of atomicity and minimality, identified by both of my predecessors, Bale, Gagnon \& Khanjian (2011a) and Scontras (2014), as crucial in explaining the data, in the morphosyntax of natural languages, in the form of semanticallycontentful, morphosyntactic features. This is done in such a way that both the cross-linguistic typology of grammatical number and the properties of the numeral+noun construction are explained by one and the same set of tools.

The organization of the paper is as follows. In Section 2, I present my account of Table 1, introducing first the basic assumptions of Harbour (2014) and Scontras (2014) that it relies on. In Section 3, I compare my proposal to Scontras's. In Section 4, I compare it to Bale, Gagnon \& Khanjian's (2011) account. Section 5 is the conclusion.

\section{Semantics and number marking in the numeral+noun construction}

\subsection{Background: Harbour 2011, 2014 and Scontras 2014}

There are two main ingredients to the account I will propose. The first ingredient is Harbour's $(2011,2014)$ number features. The second is Scontras's (2014) syntactic assumptions about the numeral-noun construction, as well as the crucial role that number features play in deriving not only the correct semantics for it, but the correct number marking on the noun that accompanies the numeral, as seen in Table 1. 
Languages make grammatical number distinctions beyond the familiar singular and plural, such as dual, trial, minimal, augmented, paucal, or greater plural, among others (see Corbett 2000). In addition, as we know at least since Greenberg (1966), there is a typology of grammatical number, so that not all possible number value combinations lead to attested linguistic systems; e.g., there are no attested number systems that distinguish singular from dual only, or paucal from plural only, or trial from plural only, etc. The full set of generalizations is in (7) (from Harbour 2014: p. 186):

(7) Trial requires dual

Dual requires singular

Singular requires plural

Plural requires singular or minimal

Unit augmented requires augmented

Minimal requires augmented or plural

Augmented requires minimal

Greater paucal requires (lesser) paucal

Paucal requires plural

(Greater (and global) plural requires plural or augmented

The challenge for a theory of number is to explain why only a subset of the logically possible combinations of number values leads to attested number systems in the languages of the world. Harbour 2014 is one such theory, and it is this theory that I use in my proposal below.

Harbour (2014) postulates three different, semantically contentful features, [ \pm additive], [ \pm atomic], [ \pm minimal], and, together with the following assumptions, derives the cross-linguistic typology implied in (7): (a) NumberP $\mathrm{P}^{11}$ takes $\mathrm{nP}$ as complement, as in (8); (b) $\mathrm{n}^{\mathrm{o}}$, the head of $\mathrm{nP}$, assigns roots to the category of nouns and structures them into semilattices; (c) up to three features can appear in Number ${ }^{\circ}$, the head of NumberP, either alone or in combination with each other: [ \pm additive], [ \pm atomic], [ \pm minimal]; $(d)$ these features operate on the lattices provided by nP; (e) the repetition of a particular feature in Number ${ }^{\circ}$ may or may not be allowed in a language; and (f) the semantic range of the [ \pm additive] cut is subject to social convention. Not all of these assumptions are new to Harbour's work; in particular, the struc-

11 Given the varied ways in which authors designate the head that hosts number features, I've decided to call it simply Number ${ }^{\circ}$. It is \# in Scontras 2014 (see Section 3), $\Phi$ in Sauerland 2003, and $\mathrm{Num}^{\circ}$ in Harbour 2014. The term 'noun phrase' as used in this paper is merely descriptive. 
tural assumptions and the function of $\mathrm{n}^{\circ}$ and $\mathrm{nP}$ are quite common in the literature (see Borer 2005 and much subsequent work). We will consider only certain aspects of these assumptions here, as not all of them are relevant in what follows; for example, we will ignore the feature [ \pm additive] (hence also (f)), since this feature is only involved in the generation of values, such as paucal, which do not concern us here.

Consider the structure in (8), assumed to be part of the structure of noun phrases:

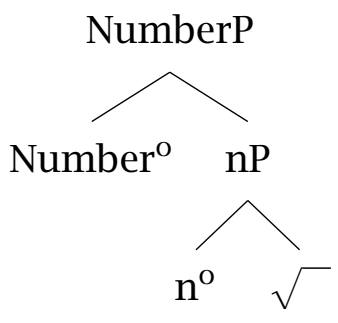

At the bottom of the projection is a root, $\sqrt{ }$. After $n^{0}$ operates on it, we obtain a join semilattice, so, for three individuals $\mathrm{a}, \mathrm{b}$ and $\mathrm{c}$, we have: ${ }^{12}$

(9) $\llbracket \mathrm{nP} \rrbracket=\{\mathrm{a}, \mathrm{b}, \mathrm{c}, \mathrm{ab}, \mathrm{ac}, \mathrm{bc}, \mathrm{abc}\}$

The compositional semantics for the number features is as follows: ${ }^{13}$

$$
\begin{aligned}
& \llbracket+\text { atomic } \rrbracket=\lambda P . \lambda x . P(x) \& \operatorname{atom}(x) \\
& \llbracket \text {-atomic } \rrbracket=\lambda P . \lambda x . P(x) \& \neg \operatorname{atom}(x)
\end{aligned}
$$

12 Harbour (2014) is not explicit about the denotations of roots - however, this issue is orthogonal to our purposes, as what matters to us is what the meaning of $\mathrm{nP}$ is, not how that meaning is arrived at.

13 Following Martí (2020), I treat the contribution of number features to be entirely made up of entailments, whereas for Harbour $(2011,2014)$ some of the content of some features is presupposed. For example, his actual semantics for [ \pm minimal] is as follows:

$$
\llbracket+\text { minimal } \rrbracket=\lambda \mathrm{P} . \lambda \mathrm{x}: \mathrm{P}(\mathrm{x}) . \neg \exists \mathrm{y} \mathrm{P}(\mathrm{y}) \& \mathrm{y} \sqsubset \mathrm{x}
$$

$$
\llbracket-\text { minimal } \rrbracket=\lambda P . \lambda x: P(x) . \exists y \mathrm{P}(y) \& y \sqsubset x
$$

Nothing of what I say here depends on this, since in (i) the main effect of the features is still an entailment. For consistency with [ \pm minimal], I assume that [ \pm atomic] is also of type $<$ et, et $>$, not $<\mathrm{e}, \mathrm{t}\rangle$ as in Harbour's proposal, but, again, this difference has no consequences. $\sqsubset$ is the proper subpart relation. Lower case variable names range over both atomic and non-atomic individuals. 


$$
\begin{aligned}
& \llbracket+\text { minimal } \rrbracket=\lambda \mathrm{P} . \lambda \mathrm{x} . \mathrm{P}(\mathrm{x}) \& \neg \exists \mathrm{y} \mathrm{P}(\mathrm{y}) \& \mathrm{y} \sqsubset \mathrm{x} \\
& \llbracket \text {-minimal } \rrbracket=\lambda \mathrm{P} . \lambda \mathrm{x} . \mathrm{P}(\mathrm{x}) \& \exists \mathrm{y} \mathrm{P}(\mathrm{y}) \& \mathrm{y} \sqsubset \mathrm{x}
\end{aligned}
$$

[ \pm Atomic $]$ is sensitive to atoms $([+$ atomic $])$ vs. non-atoms ([-atomic $])$. [ \pm Minimal] is sensitive to individuals with minimal parts ([-minimal]) vs. without $([+$ minimal $])$ in the set that is a sister of the number feature. [ \pm Atomic] and [ \pm minimal] correspond to the notions of atomicity and minimality, respectively, notions which are well known in the literature on the semantics of plurality. The difference is that, here, atomicity and minimality are embodied in features that play a role in the morphosyntax as well as in the semantics. It is important to bear this difference in mind in what follows.

Consider a singular-plural system, with trees as in (12) and (13) (trees accompanied by the denotation of their top node for ease of reference):
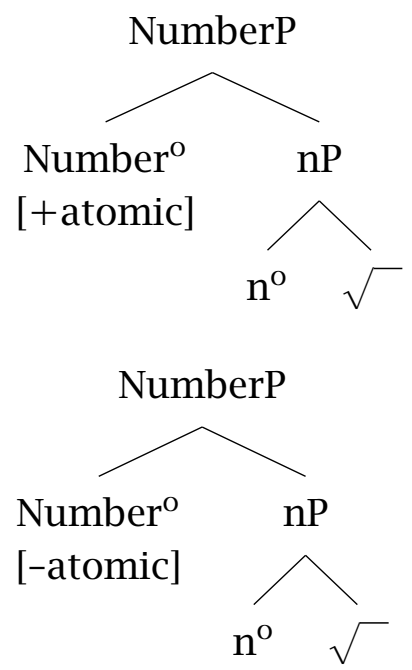

$\lambda \mathrm{x} . \llbracket \mathrm{nP} \rrbracket(\mathrm{x}) \& \neg \mathrm{atom}(\mathrm{x})=\{\mathrm{ab}, \mathrm{bc}, \mathrm{ac}, \mathrm{abc}\}$

(12) is the representation of a singular noun phrase, and (13), of a plural noun phrase. We obtain (14) and (15) as the denotation of NumberP in (12) and (13), respectively:

(14) $\llbracket$ NumberP $\rrbracket=\llbracket+$ atomic $\rrbracket(\llbracket n P \rrbracket)$

$$
=\lambda \mathrm{x} \cdot \llbracket \mathrm{nP} \rrbracket(\mathrm{x}) \& \operatorname{atom}(\mathrm{x})=\{\mathrm{a}, \mathrm{b}, \mathrm{c}\}
$$

(denotation of (12))

(15) $\llbracket$ NumberP $\rrbracket=\llbracket$-atomic $\rrbracket(\llbracket n P \rrbracket)$

$$
=\lambda \mathrm{x} \cdot \llbracket \mathrm{nP} \rrbracket(\mathrm{x}) \& \neg \mathrm{atom}(\mathrm{x})=\{\mathrm{ab}, \mathrm{bc}, \mathrm{ac}, \mathrm{abc}\} \quad \text { (denotation of (13)) }
$$

The structure that gives rise to (15), i.e., to exclusive plural interpretations, contains a [-atomic] feature. I will not question the resulting exclusive 
interpretation of the plural in (15) for now but will come back to it in Section 3. In English, a [ \pm atomic] number system, [+atomic] is not morphologically realized overtly, but [-atomic] is, as -s. It will be important to keep in mind in what follows that, in this approach, grammatical number is a property of noun phrases, not nouns, and that the relationship between number and nouns is indirect and mediated by the syntax.

[ \pm Minimal] is sensitive to elements with parts ([-minimal]) vs. elements without parts $([+$ minimal $])$ in its complement. Importantly, $[ \pm$ minimal $]$ is a relative notion: whether an individual counts as [+minimal] or not, for example, depends on what else is in the set that the feature operates on. This property of $[ \pm$ minimal] will play a crucial role in my account in Section 2.2. For now, note that, in the case of (16), since the sister of Number ${ }^{\circ}$ is $\mathrm{nP}$ and $\mathrm{nP}$ is as in (9), the results will be indistinguishable from (12)/(14) and (13)/(15), respectively:

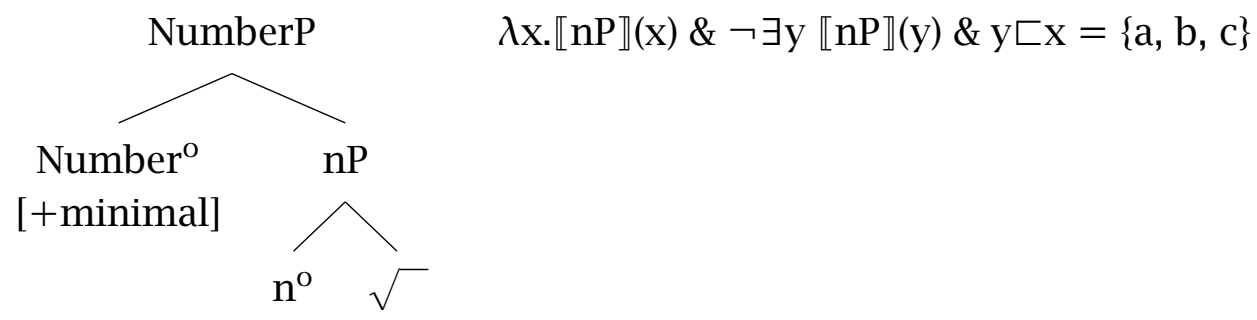

(17)

$$
\begin{aligned}
& \text { NumberP } \quad \lambda \mathrm{x} . \llbracket n \mathrm{nP} \rrbracket(\mathrm{x}) \& \exists \mathrm{y} \llbracket \mathrm{nP} \rrbracket(\mathrm{y}) \& \mathrm{y} \sqsubset \mathrm{x}=\{\mathrm{ab}, \mathrm{bc}, \mathrm{ac}, \mathrm{abc}\} \\
& \text { Number }^{\mathrm{O}} \\
& \llbracket+\operatorname{minimal} \rrbracket(\llbracket \mathrm{nP} \rrbracket)=\lambda \mathrm{x} . \llbracket \mathrm{nP} \rrbracket(\mathrm{x}) \& \neg \exists \mathrm{y} \llbracket \mathrm{nP} \rrbracket(\mathrm{y}) \& \mathrm{y} \sqsubset \mathrm{x} \\
& =\{\mathrm{a}, \mathrm{b}, \mathrm{c}\} \\
& \text { (denotation of (16)) } \\
& \text { (19) } \quad \llbracket \text {-minimal } \rrbracket(\llbracket n P \rrbracket)=\lambda x . \llbracket n P \rrbracket(x) \& \exists y \llbracket n P \rrbracket(y) \& y \sqsubset x \\
& =\{\mathrm{ab}, \mathrm{bc}, \mathrm{ac}, \mathrm{abc}\} \\
& \text { (denotation of (17)) }
\end{aligned}
$$

The set of elements in $\llbracket \mathrm{nP} \rrbracket$ for which there aren't proper subparts in $\llbracket \mathrm{nP} \rrbracket$ is equivalent to the set of atoms in $\llbracket \mathrm{nP} \rrbracket$, and the set of elements in $\llbracket \mathrm{nP} \rrbracket$ for which there are proper subparts in $\llbracket \mathrm{nP} \rrbracket$ is equivalent to the set of non-atoms in $\llbracket \mathrm{nP} \rrbracket$. Thus, (16) may also be associated with what descriptively we can call singular noun phrases, and (17), with plural noun phrases. That is, what are 
descriptively singular-plural number systems may in principle be analyzed as in $(12) /(13)$ or as in $(16) /(17)$. Given the crucial role that both [ \pm atomic] and [ \pm minimal] play in my account of the numeral+noun construction, I will review arguments in favour of the idea that we do indeed need both features.

First, it is not the case that [ \pm minimal] gives the same result as [ \pm atomic] in all cases. The derivation of systems that have a dual number value in Harbour 2011, 2014, based on Noyer 1992, involves the feature [ \pm minimal] in combination with [ \pm atomic]. Consider the syntax in (20) (I have numbered the two NumberPs for convenience), which represents the internal syntax of singular, dual and plural noun phrases in languages with a singular-dualplural system, and the feature values in (21):

(20)

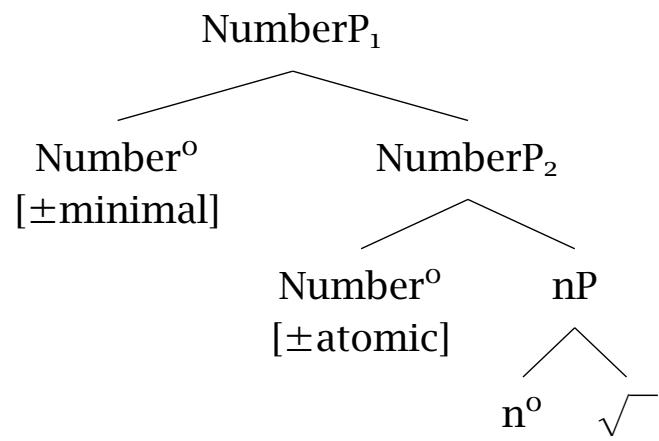

$$
\begin{aligned}
& \text { a. } \llbracket+\text { minimal } \rrbracket(\llbracket+\text { atomic } \rrbracket(\llbracket \mathrm{nP} \rrbracket))=(\text { singular }) \\
& =\lambda \mathrm{x} . \llbracket \mathrm{nP} \rrbracket(\mathrm{x}) \& \text { atom }(\mathrm{x}) \& \neg \exists \mathrm{y} \text { atom }(\mathrm{y}) \& \mathrm{y} \sqsubset \mathrm{x} \\
& \text { b. } \quad \llbracket+\text { minimal } \rrbracket(\llbracket \text {-atomic } \rrbracket(\llbracket \mathrm{nP} \rrbracket))=(\text { dual }) \\
& =\lambda \mathrm{x} \cdot \llbracket \mathrm{nP} \rrbracket(\mathrm{x}) \& \neg \operatorname{atom}(\mathrm{x}) \& \neg \exists \mathrm{y} \neg \operatorname{atom}(\mathrm{y}) \& \mathrm{y} \sqsubset \mathrm{x} \\
& \text { c. } \quad \llbracket \text {-minimal } \rrbracket(\llbracket \text {-atomic } \rrbracket(\llbracket \mathrm{nP} \rrbracket))=(\text { plural })
\end{aligned}
$$

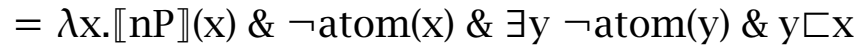

$$
\begin{aligned}
& \text { d. } \# \llbracket \text {-minimal } \rrbracket(\llbracket+\text { atomic } \rrbracket(\llbracket n \mathrm{nP} \rrbracket))=
\end{aligned}
$$

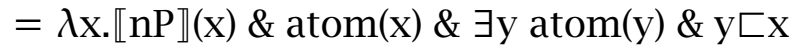

The feature combination in (21a) gives rise to the singular, that in (21b), to the dual, and that in $(21 \mathrm{c})$, to the plural. Importantly, consider how the dual in (21b) is derived: [-atomic] first eliminates the atoms from $\mathrm{nP}$, and [+minimal] then chooses, from the set of non-atoms so provided by $\mathrm{NumberP}_{2}$, all of those constituted of two atoms, since these are the individuals with no proper subparts in NumberP ${ }_{2}$. In (21c), for plural, of the set of non-atoms provided by NumberP ${ }_{2}$, [-minimal] chooses all of those constituted of three or more atoms, since these are the individuals with at least one proper subpart in NumberP ${ }_{2}$, correctly for plurals in languages that have a dual (see 
Martí 2020 for ample discussion of this point). Since nothing can satisfy (21d) (atoms do not have proper subparts), (21d) does not give rise to a well-formed meaning, and thus, by assumption, to any number value. ${ }^{14}$ Thus, singulardual-plural number systems constitute evidence for the existence of both [ \pm atomic] and [ \pm minimal] as separate features (see Nevins 2011 for recent arguments for this decompositional account of dual number).

Another argument for the postulation of a [ \pm minimal] feature concerns number systems with a first person inclusive/exclusive distinction. Consider the ergative enclitic pronominal forms of Ilocano, an Austronesian language spoken in the Philippines, in Table 2 (Corbett 2000: p. 168, Rubino 1997: pp. 55-6):

\begin{tabular}{llll} 
& singular & dual & plural \\
\hline 1ex & -ko & - & - mi \\
lin & - & -ta & -tayo \\
2 & - mo & - & - yo \\
3 & -na & - & - da
\end{tabular}

Table 2 Traditional analysis of Ilocano pronominal forms

Ilocano distinguishes two types of first person pronouns: exclusive (1ex), which exclude the addressee, and inclusive (1in), which include the addressee. That is, Ilocano is a language that has different types of we: for example, it uses - $m i$ for cases where the addressee is excluded ('we excluding you'), and -tayo, for those where it is included ('we including you'). Interestingly, Ilocano has a third form -ta which is inclusive, so it includes the addressee, but it is only possible to use it to refer to the speaker-hearer dyad, that is, to a twosome - hence the label dual in Table 2. However, the analysis in Table 2 misses an important generalization: if -ta is a dual form, it is a strange one, in that we expect a full paradigm, with dual versions of the pronoun system for first person exclusive, second person, and third person. Positing a traditional singular-dual-plural number system for Ilocano pronouns leaves the reason behind the empty cells in the table unexplained. Positing a [ \pm minimal] sys-

14 I follow Gajewski's (2002) notion of L-analyticity in deriving ungrammaticality from triviality. In particular, sentences containing (21d) (and all others designated with the hash tag) will be trivially false in virtue of their logical structure. This makes them L-analytic, which in turn makes them ungrammatical. 


\begin{tabular}{lll} 
& minimal & augmented \\
\hline 1ex & -ko & -mi \\
in & -ta & -tayo \\
2 & -mo & -yo \\
3 & -na & -da
\end{tabular}

Table $3 \quad[ \pm$ minimal $]$ analysis of Ilocano pronominal forms

tem instead (a minimal-augmented system in traditional terms) obviates the need for such stipulative explanations:

The minimal pronouns are the ones that are derived with the feature [+minimal $]$ - that the referent of $-t a$ is a twosome follows naturally from this, as the speaker-hearer dyad is the most 'minimal' individual in $\mathrm{P}$ that satisfies the requirements of the first person inclusive (recall: the first person inclusive has to include the speaker, because it is first person, and the addressee, because it is inclusive). That is, of the set of all individuals in $P$ that satisfy the first person inclusive requirements, which will include speaker+hearer+other , $_{\text {, }}$ speaker +hearer + other $_{1}+$ other $_{2}$ and so on, in addition to speaker +hearer, speaker +hearer is the only individual without proper subparts. This obviates the need to postulate a rare dual that only has a first person inclusive form in this analysis. The augmented pronouns are the ones derived with the feature [-minimal]. Notice that in the case of the first person inclusive, this has the effect that -tayo ('we including you') is concerned with triples (as it is predicted to pick, of those individuals that satisfy the first person inclusive requirements, those which in addition have proper subparts, thus excluding the dyad speaker+hearer) - this is, in fact, empirically correct. Thus, there are languages for which an analysis as [ \pm minimal] number systems, not as [ \pm atomic] systems, is entirely justified.

At this point one might worry that, while there is evidence for the postulation of [ \pm minimal], as we've seen, there isn't actually evidence for [ \pm atomic]. [ \pm Minimal] is enough to derive both minimal-augmented systems and singularplural systems. And singular-dual-plural systems could be generated as long as [ \pm minimal] can repeat, so there would be no need to appeal to [ \pm atomic] to generate such systems: 
(22)

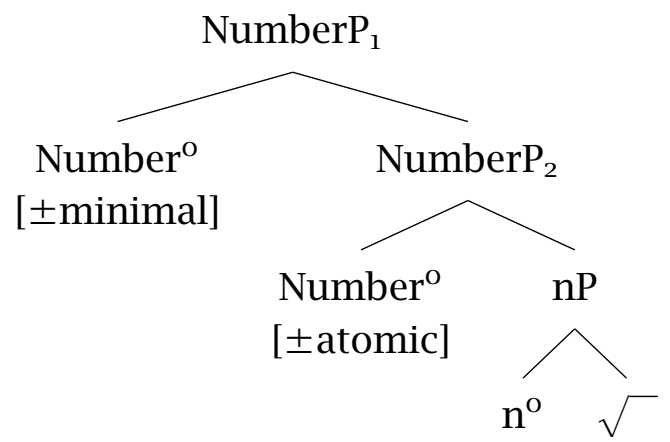

(23) a. [+minimal, +minimal $]$

(singular)

b. [+minimal, -minimal]

(dual)

c. [-minimal, -minimal]

(plural)

Indeed, more complicated minimal-augmented number systems require [ \pm minimal] to repeat. This is the case, for example, for the dative pronoun system of Rembarrnga, an Australian aboriginal language, in Table 4 (Corbett 2000: pp. 166-167, McKay 1978, 1979). In Harbour's 2011, 2014 analysis, Rembarrnga dative pronouns repeat [ \pm minimal] to generate the number value 'unit augmented' ("one more than minimal", which is two for all persons except for first person inclusive, where it is three), as shown in (24):

\begin{tabular}{llll} 
& minimual & unit augmented & augmented \\
\hline 1ex & ngtnt & yarrbbarrah & yarrt \\
1in & ytkkt & ngakorrbbarrah & ngakorrt \\
2 & kut & nakorrbbarrah & nakorrt \\
3 & nawt,ngadt & barrbbarrah & barrt
\end{tabular}

Table 4 Rembarrnga dative pronouns

(24) $\quad[+$ minimal $]$

[+minimal, -minimal]

[-minimal] (minimal) (unit augmented) (augmented)

Another example is number systems that include a trial number value, such as Larike, an Austronesian language of Indonesia (Corbett 2000: pp. 2122, Laidig \& Laidig 1990), with the analysis in (25): 


\begin{tabular}{lllll} 
& singular & dual & trial & plural \\
\hline 1ex & a?u & arua & aridu & ami \\
1in & - & itua & itidu & ite \\
2 & ane & irua & iridu & imi \\
3 & mane & matua & matidu & mati
\end{tabular}

Table 5 Larike pronouns

(25) [+minimal, +atomic $]$

(singular)

[+minimal, -atomic]

(dual)

[-minimal, -atomic]

(plural)

[+minimal, -minimal, -atomic]

(trial)

However, if we allow the plural in a system like that in (23) to be generated with a feature combination such as [-minimal, -minimal], or trial to be generated as [+minimal, -minimal, -minimal] as in (25), where the same value (negative) of the minimal feature repeats, nothing prevents the generation of many unattested number values, such as quadrals, quintals, sextals, and so on (see Corbett 2000: pp. 26-30):

$$
\begin{aligned}
& \text { [+minimal, -minimal, -minimal, -minimal] } \\
& \text { [+minimal, -minimal, -minimal, -minimal, -minimal }] \text { (cuadral) } \\
& \text { [+minimal, -minimal, -minimal, -minimal, -minimal, -minimal] }
\end{aligned}
$$

(sextal)

To prevent these unattested number values from being generated, feature repetition in Harbour's account is constrained so that it can only apply if the value of the feature is not the same (e.g., [+minimal, -minimal] is allowed, but [-minimal, -minimal] isn't). This entails that [ \pm atomic] is necessary after all, since otherwise we'd lose an account of number systems with duals, or with duals and trials. Returning to the main argument, then, both [ \pm minimal] and $[ \pm$ atomic] are necessary ingredients of the theory.

My account of the patterns in Table 1 makes use of certain crucial assumptions from Scontras (2014) as well. Scontras assumes that number features in Number ${ }^{\mathrm{O}}$ (in his case, [SG] and [PL]; see Section 3) operate on constituents that contain the numeral, that is, on NumeralP in (27) (NumP for Scontras; I've adapted his labels to Harbour's and my account here, but see Section 3): 
(27)

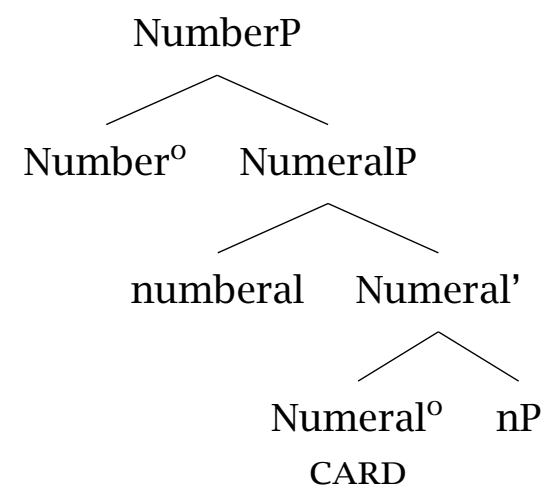

Like Harbour, he assumes that these features are responsible for the number morphology we see on noun phrases. In fact, which features are assumed to operate in Number ${ }^{\circ}$ in different languages plays a crucial role in his account, as well as in mine, as we will see below. Scontras also assumes that numerals denote numbers, of type n, following Hackl (2001), Krifka (1995), Rothstein (2011) and others. They occupy the specifier position of NumeralP, a projection headed by $\mathrm{Numeral}^{\mathrm{O}}$, occupied by the cardinality predicate CARD, and with $\mathrm{nP}$ as its syntactic argument. ${ }^{15}$ The semantics of CARD is as follows, also as in Hackl 2001 and others: ${ }^{16}$

$$
\llbracket \mathrm{CARD} \rrbracket=\lambda \mathrm{P} \lambda \mathrm{n} \lambda \mathrm{x} . \mathrm{P}(\mathrm{x}) \& \# \mathrm{x}=\mathrm{n}
$$

\# is an atom-counting function. CARD takes a predicate $\mathrm{P}$ and a number $\mathrm{n}$ and returns the set of individuals in $\mathrm{P}$ each of which is constituted of exactly $\mathrm{n}$ atoms.

These are the tools from Harbour (2014) and Scontras (2014) that I will use in my account below. It was important to introduce Harbour's theory in some detail because the strength of my argument depends on it: the independent justification of my proposal rests on the wide empirical coverage his theory is capable of achieving.

15 Scontras argues that NumeralP (his NumP) is more generally MeasureP, and that units of measurement other than cardinality (e.g., for weight, volume, length...) are possible. I put measure phrases aside here (cf. Acquaviva 2005, Rothstein 2017 for arguments that NumeralPs and MeasurePs are different). It is possible that my proposal in Section 2.2 cannot maintain the generality regarding units of measurement that Scontras's account accomplishes, a matter I leave for future research.

16 (28) does not existentially quantify over individuals, which CARD is assumed to do in other accounts. Existential quantification can be carried out by a (silent) quantifier higher up in the structure. 


\subsection{Proposal}

I propose that type 1 languages, such as English, are [ \pm atomic] systems; that type 2 languages, such as Turkish, are [ \pm minimal] systems; and that type 3 languages, such as Western Armenian, have access to two number systems, a [ \pm atomic] one and a [ \pm minimal] one. In what follows, I first show how the patterns in Table 1 are derived from the assumptions in Section 2.1. I then comment on the plausibility of Turkish number being a [ \pm minimal] system, and, finally, on the idea that a language may have two number systems at its disposal but deploy only one of them at any given time, which is a crucial aspect of my analysis of type 3 languages.

A type 1 language, such as English, is derived as follows. First, assume that [+atomic] spells out as $\varnothing$, and [-atomic], as $-s .{ }^{17}$ We then have (29) for the nP boy, (30) for singular and plural noun phrases with the root boy, and (31) for phrases with a numeral and with the same root:

(29) $\llbracket\left[{ }_{n P} b o y\right] \rrbracket=\{a, b, c, a b, b c, a c, a b c\}$

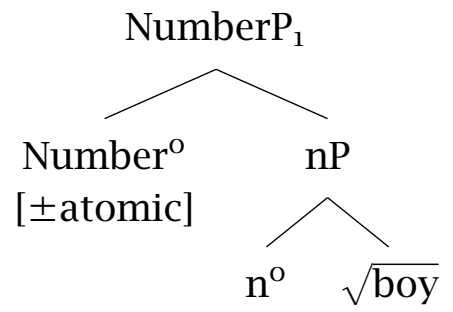

(31)

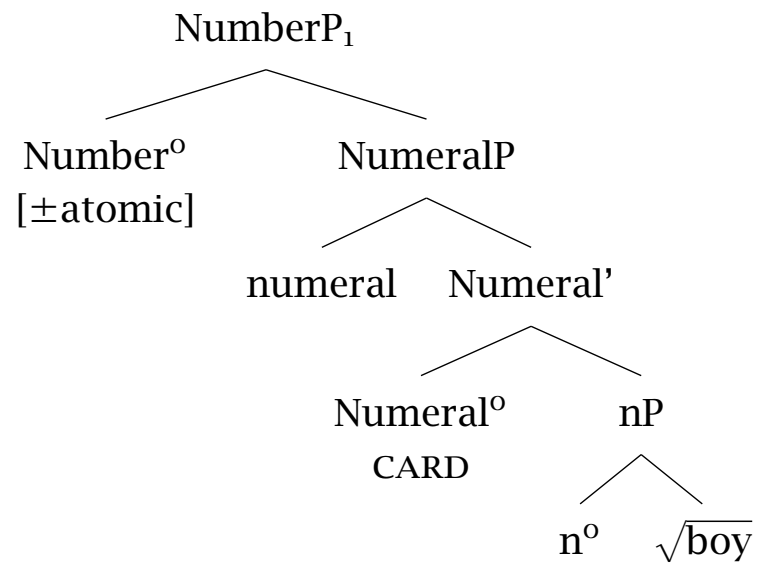

17 My proposal is compatible with languages that may actually have an overt singular morphological marker, of course. The spell out of [-atomic] in irregular plurals (e.g., English sheep, mice, geese, etc.) is accomplished via other morphological processes, such as null affixation, root change, etc. 
These assumptions give rise to the following results:
a. $\quad \llbracket[+$ atomic $][n p$ boy $] \rrbracket=\lambda x . \llbracket[n p$ boy $] \rrbracket(x)$ and atom(x)
$\rightarrow$ boy
b. $\quad \llbracket[-$ atomic $]\left[{ }_{n p}\right.$ boy $] \rrbracket=\lambda x \cdot \llbracket[n p$ boy $] \rrbracket(x)$ and $\neg$ atom $(x)$
$\rightarrow$ boys

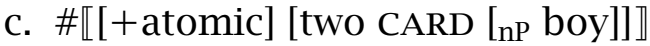
$\rightarrow$ two boy

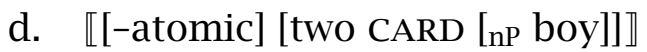
$=\lambda \mathrm{x} \cdot \llbracket[\mathrm{np}$ boy $] \rrbracket(\mathrm{x}) \& \operatorname{card}(\mathrm{x})=2$
$\rightarrow$ two boys
e. $\llbracket[+$ atomic] [one CARD [np boy $] \rrbracket$
$=\lambda \mathrm{x} \cdot \llbracket[\mathrm{np}$ boy $] \rrbracket(\mathrm{x}) \& \operatorname{card}(\mathrm{x})=1$
$\rightarrow$ one boy

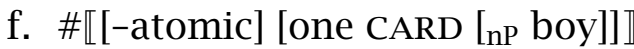
$\rightarrow$ one boys

(32a) is the only source for morphologically singular noun phrase boy and delivers the correct semantics for it. (32b) gives rise to the morphologically plural noun phrase boys and assigns it an exclusive plural semantics, which I return to in Section 3. (32c) denotes the empty set and is thus ill-formed. It is also the only source for two boy, so two boy is correctly predicted to be ungrammatical in English (hence the resulting phrase is crossed out in (32c); what follows an arrow in (33), and (36) below, is always a phrase). (32d), with [-atomic] in Number ${ }^{\circ}$, is the only source for two boys and gives rise to its desired semantics. (32e) is the only well-formed source for one boy, and it, again, gives rise to the correct semantics. (32f) is empty and ill-formed, and the only possible source for one boys, which is thus predicted to be ungrammatical. Thus, we derive that in type 1 languages, all numerals greater than one appear in morphologically plural noun phrases, and the numeral one appears in morphologically singular noun phrases. Phrases without a numeral, such as boy and boys, are morphologically and semantically singular or plural noun phrases, respectively. Notice that the root $\sqrt{\text { boy }}$ and the nP boy are not numbered $-\mathrm{nP}$ is always number-neutral in this system ((29)). However, the noun phrase boy is numbered, as it contains a number feature, and thus a Number Phrase ((30), (32a)). It is because of the latter that we can say that in this analysis morphologically singular noun phrases like English boy are treated as semantically singular or [+atomic] (likewise, morphologically plural noun phrases like boys are treated as semantically plural or [-atomic]).

Languages of type 2 are, instead, [ \pm minimal] systems. Assume that in Turkish, [+minimal] spells out as $\varnothing$ and [-minimal] spells out as -LAr. We thus have:

$$
\llbracket[n p \text { çocuk }] \rrbracket=\{a, b, c, a b, b c, a c, a b c\}
$$


(34)

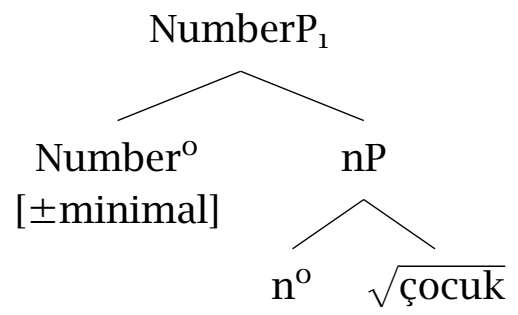

(35)

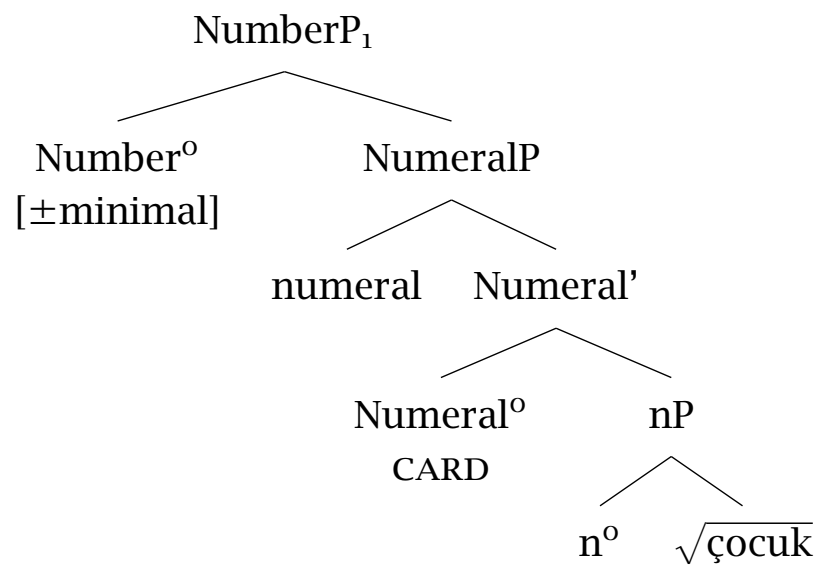

(36) a. $\llbracket[+$ minimal] [np çocuk $] \rrbracket$

$=\lambda \mathrm{x} . \llbracket\left[{ }_{n P}\right.$ çocuk $] \rrbracket(\mathrm{x}) \& \neg \exists \mathrm{y} \llbracket\left[{ }_{n P}\right.$ çocuk $] \rrbracket(y) \& \mathrm{y}<\mathrm{x} \quad \rightarrow$ çocuk

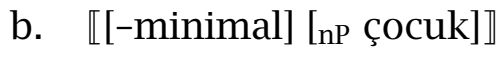

$=\lambda \mathrm{x} \cdot \llbracket[$ np çocuk $] \rrbracket(\mathrm{x}) \& \exists \mathrm{y} \llbracket[\mathrm{n}$ çocuk $] \rrbracket(\mathrm{y}) \& \mathrm{y}<\mathrm{x} \quad \rightarrow$ çocuklar

c. $\llbracket$ iki CARD $\left[{ }_{n P}\right.$ çocuk $] \rrbracket=\lambda x$. $\llbracket[n p$ çocuk $] \rrbracket(x) \& \operatorname{card}(x)=2$

d. $\llbracket\left[+\right.$ minimal] [iki CARD $\left[{ }_{n P}\right.$ çocuk $\left.]\right] \rrbracket=\lambda x$. $\llbracket$ iki CARD $\left[{ }_{n P}\right.$ çocuk $] \rrbracket(x) \&$ $\neg \exists \mathrm{y} \llbracket$ iki CARD [nP çocuk] $](y) \& \mathrm{y}<\mathrm{x} \quad \rightarrow i k i$ çocuk

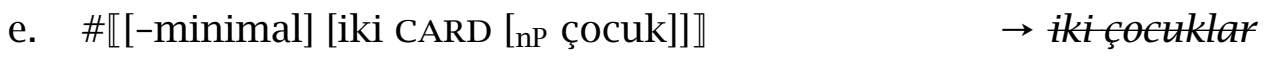

f. 【bir CARD [np çocuk]】

$=\lambda \mathrm{x} \cdot \llbracket[\mathrm{np}$ çocuk $] \rrbracket(\mathrm{x}) \& \operatorname{card}(\mathrm{x})=1$

g. 【[+minimal] [bir CARD [np çocuk $]] \rrbracket$

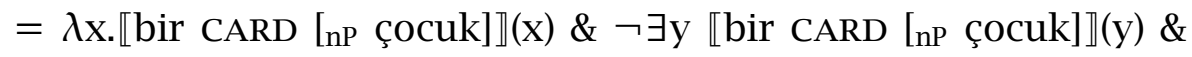
$\mathrm{y}<\mathrm{x} \rightarrow$ bir çocuk

h. \#【[-minimal] [bir CARD [np çocuk $]] \rrbracket \rightarrow$ bir çocuklar

(36a) and (36b) correspond to the semantics and number marking of noun phrases without a numeral - they give rise to, descriptively speaking, a singularplural number system. (36b) gives rise to an exclusive plural semantics, which I return to in Section 3 . The effects of [ \pm minimal] are more noticeable in (36e), which denotes a set of boy individuals composed of exactly two atoms, these 
two-atom, plural boy individuals having no proper subparts in (36d) (which contains only plural boy individuals composed of exactly two atoms). (36g) denotes a set of boy individuals composed of exactly one atom, these atomic boy individuals having no proper subparts in (36g) (which contains only boy atoms). These are the only sources for the grammatical iki çocuk 'two boys' and bir çocuk 'one boy', respectively, which also result in the correct semantics. Crucially, no matter what numeral is present in the phrase, [-minimal], which spells out as -lAr, never gives rise to a well-formed result ((36f) and (36h) denote the empty set) - that is because [-minimal] selects from its input $\mathrm{P}$ those individuals that have proper subparts in $\mathrm{P}$, and there are no such

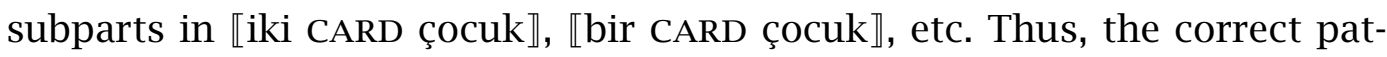
tern is generated for type 2 languages from the assumptions made above. The only difference in this account between languages of type 1 and languages of type 2 is in the number feature that appears in Number ${ }^{0}-$ if that feature is [ \pm minimal], as opposed to [ \pm atomic], one and all numerals greater than one will only be able to appear in morphologically singular noun phrases. Notice, again, that the root, e.g., $\sqrt{\operatorname{cocuk}}$, and the $\mathrm{nP}$, çocuk, are not numbered. However, the noun phrase çocuk is. Thus, in this analysis, morphologically singular noun phrases like Turkish çocuk are treated as semantically singular or [+minimal] (likewise, morphologically plural noun phrases like çocuklar are treated as semantically plural or [-minimal]).

Finally, languages of type 3 have at their disposal both a [ \pm minimal] number system and a [ \pm atomic] number system for Number ${ }^{\circ}$. In Western Armenian, [+minimal] and [+atomic] spell out as $\varnothing$, and [-minimal] and [-atomic] spell out as $-(n) e r$. This entails, first of all, that there are two sources for a morphologically singular noun phrase like dəgha, both of them resulting in semantic singularity: either (32a) or (36a). Likewise, there are two sources for the morphologically plural noun phrase dəghaner: either (32b) or (36b) both of them give rise to an exclusive plural semantics.

[ \pm Minimal] and [ \pm atomic], however, do not combine in this system - this ensures that Western Armenian is correctly predicted not to have a dual (cf. discussion in Section 2.1), but to give rise to the language type 2 ((36)) and the language type $1((32))$ patterns with numerals. When [ \pm atomic] is chosen for Number ${ }^{\circ}$, the type 1 pattern follows. Notice, in particular, that [+atomic] cannot be the feature involved in the generation of yergu dagha 'two boys', since (32c) is ill-formed. However, a language like Western Armenian in this account may choose to use [ \pm minimal] in Number ${ }^{\circ}$ instead, and (36e), which uses [+minimal], results in the correct form and meaning for yergu dogha. 
Likewise, [-minimal] cannot be the feature involved in the derivation of yergu dəghaner 'two boys', since (36f) uses this feature and is ill-formed. However, (32d) is also allowed in Western Armenian, and the correct form and meaning for yergu dəghaner results. Since both (32f) and (36h) are ill-formed, and since there is no other source for meg dəghaner 'one boys', meg dəghaner is predicted to be ungrammatical. Meg dəgha 'one boy' has two sources, (32e) and $(36 \mathrm{~g})$, both of which give rise to the correct semantics. Thus, languages of type 3 are a mix between types 1 and 2 .

If this analysis is correct, then languages of type 2 are not [ \pm atomic] systems but [ \pm minimal] systems. The next question is whether there are other parts of the grammar of these languages where we can detect that $[ \pm$ minimal] is at work. One place to look, recalling now Section 2.1, is in their pronoun system - if exclusive first person is distinguished from inclusive first person, then [ \pm minimal] is being used in the language. Unfortunately, Turkish does not distinguish exclusive vs. inclusive first person in its pronoun system (see Kornfilt 1997: p. 281), where a simple singular vs. plural distinction is made. The pronoun data on its own is thus compatible with Turkish being either a [ \pm atomic] system or a $[ \pm$ minimal] system. Other languages that I hypothesize to be of type 2, such as Finnish (Karlsson 1982: p. 74) or Hungarian (Tompa 1968: p. 61) do not distinguish exclusive vs. inclusive first person either, and neither do Western Armenian or Miya (Schuh 1998: p. 187), languages of type 3 .

However, type 2 or type 3 languages with an inclusive vs. exclusive first person distinction do exist. For example, Itzaj Maya (Hofling 2000) is a candidate for a type 3 language. Itzaj Maya makes a distinction on several of its pronoun series between inclusive and exclusive first person, which in Harbour's system requires the feature [ \pm minimal]. We thus have evidence for [ \pm minimal] in Itzaj Maya that is independent of the numeral+noun construction. In addition, this language makes an obligatory singular-plural distinction on its nouns (Hofling 2000: p. 118). Importantly, when nouns combine with numerals, they may or may not take plural marking (Hofling 2000: p. 227), as in Western Armenian. In my approach, this is because the noun system of Itzaj Maya has access to either [ \pm minimal] or to [ \pm atomic], making it a type 3 language (and the singular-plural distinction on nouns, whether effected via [ \pm minimal] or [ \pm atomic], has the same surface realization, again, as in my (and Scontras's, below) analysis of Western Armenian). Thus, we 
find evidence outside of the noun system for the feature [ \pm minimal] in this language. ${ }^{18,19,20}$

In type 2 and type 3 languages with a distinction between inclusive and exclusive first person pronouns, then, the pronominal and nominal number systems both have access to the same feature, [ \pm minimal]. The final issue to address is the idea that a language would be able to use either [ \pm atomic] or [ \pm minimal], but not both at the same time. This is distinct from the claim that a language is a [ \pm atomic, \pm minimal] system; with the latter, as we saw in Section 2.1, a singular-dual-plural system is generated. The claim for languages of type 3 above is different: it is that each of [+atomic], [+minimal], [-atomic], and [-minimal], on their own, is a possible number value. The question is whether this claim is sensible within Harbour's theory. There are two issues to consider: (a) whether a language's number system could, in principle, have access to number features separately (e.g., [ \pm atomic] and $[ \pm$ minimal]), and (b) if so, how these features would be deployed in such a language. Addressing the first issue, let us notice that, in fact, Harbour's theory already assumes (a), for good empirical reasons: languages with different number distinctions in different domains (e.g., pronouns vs. nouns) do exist.

For example, in Imere (see Biggs 1975, Clark 1975, 1998, 2002 and Martí 2022), pronouns, as well as nouns inflected with the affectionate prefix series, distinguish singular, dual and plural (these domains require, featurally, [ \pm atomic] and [ \pm minimal] in Harbour's theory), but nouns inflected with a different prefix series distinguish singular, paucal and plural (featurally, this

18 Spanish-based numerals are directly followed by the noun in Itzaj Maya, without mediation of classifiers, but native, non-Spanish-based numerals must be followed by a numeral classifier (Hofling 2000: p. 141). I put constructions that use numeral classifiers aside here, though the treatment of numerals as part of a complex NumeralP assumed here is compatible with analyses of numeral classifiers as counting functions (see Bale \& Coon 2014, Krifka 1995, Wilhelm 2008 and many others).

19 Harbour (2016: p. 141) argues that hortatives (e.g., Let us go) in some languages also require [ \pm minimal]. There are in fact Turkic languages, though not Turkish itself, where there is evidence of [ \pm minimal] in hortatives (Nevskaya 2005), where the speaker-hearer dyad is treated differently from other first person inclusives (see Onambélé 2012 for other languages). Thanks to an anonymous reviewer for this point.

20 A prediction still to be confirmed is that there should be Type 3 languages in which [-atomic] and [-minimal] (or [+atomic] and [+minimal]) are not spelled out via the same morpheme. This language would look like Western Armenian or Itzaj Maya except that the plural morpheme of nouns in the numeral+noun construction, which spells out [-atomic] in these languages, would be just one of two plural morphemes: one for [-atomic], and one for [minimal]. The latter would be used elsewhere in the grammar. 
requires [ \pm atomic] and [ \pm additive]; paucal is a number value that expresses something similar to what English a few does). Thus, different classes (pronouns vs. nouns), and different subclasses within nouns, have access to different sets of number features. This suggests that the innovation needed for languages of type 3 is concerned, then, only with (b), in that, in at least some of the languages we know of, distinctions are made in one domain that are different from distinctions made in another, but for the language type 3 account above to work, two separate sets of distinctions apply in the same domain (nouns).

Interestingly, going back to Miya, mentioned in the introduction, Schuh (1989: p. 175, 1998: p. 198) shows that its animate and inanimate nouns in numeral+noun combinations behave differently. When combined with numerals greater than one, animate noun phrases, a class which includes all humans, most domestic animals and fowl and some large wild animals, cannot be morphologically singular:

(37) Miya
a. \{təvàm $\mid$ *ám $\}$ tsər (cf. 'ám wútə 'one woman') woman.PL woman.SG two
'Two women'
b. \{dlərkaw $\mid$ *dlərkiy fəđə
chicken.PL chicken.SG four
'Four chickens'
c. \{cùwàwáw| *áfuw də6ítím
goat.PL goat.SG ten
'Ten goats'

This is the language type 1 pattern. For inanimate nouns, however, both morphologically singular and plural noun phrases are possible:

(38) Miya
a. \{zəkìyáyàw $\mid$ zəkìy $\}$ vàatlə stone.PL stone.SG five 'Five stones'

b. $\quad\{$ kàmàmáw $\mid$ kàm $\} \quad$ máahà house.PL house.sG six 'Six houses' 


\section{c. $\quad\{$ kusàmámàw $\mid$ kùsàm $\}$ vàatlə mouse.PL mouse.sG five \\ 'Five mice'}

For inanimate nouns, Miya follows the Western Armenian pattern. In our terms, this entails that only [ \pm atomic] is generated in Number ${ }^{\circ}$ in animate noun phrases, whereas for inanimate noun phrases, either [ \pm atomic] or [ \pm minimal] is possible. Thus, we have a language where, overall, the number system has both [ \pm atomic] and [ \pm minimal] at its disposal, but these features are deployed differently for different nouns. According to this analysis, Miya is a mix of the patterns in language types 1 and 2, but a different mix for inanimate vs. animate nouns.

To summarize: I have proposed an analysis of the patterns in Table 1 which relies on two crucial assumptions. The first one is that Harbour's [ \pm atomic] and $\left[ \pm\right.$ minimal] may be features in Number $^{\circ}$ in the numeral+noun construction. That is, the semantic notions of atomicity and minimality are represented by the grammar as the features [ \pm atomic] and [ \pm minimal], respectively. The second is that, in the numeral+noun construction, number features operate on phrases that contain the numeral. One and the same set of tools serves to account both for the number properties of noun phrases, including those with numerals, in the three language types, and for the crosslinguistic typology of number systems.

\section{Scontras 2014}

The proposal I have made in Section 2.2 is based in Scontras's own account of the same data. However, as I show below, by combining Scontras's structure for the numeral+noun construction and his ideas about number features with Harbour's number features, as I have done above, a more principled account of the patterns in Table 1 ensues.

To be clear, my proposal owes much to Scontras's own. Yet, there is an important difference between the two: the difference is that my proposal grounds the features needed to account for the numeral+noun construction in a fully-fledged featural system (Harbour's). This move allows us to use, for the numeral+noun construction, the same analytical tools used to account for the cross-linguistic typology of number more generally - in other words, the notions of minimality and atomicity receive full independent justification once they are conceived of as Harbour's [ \pm atomic] and [ \pm minimal]. 
I show below that combining these ingredients from Harbour's and Scontras's proposals requires us to make certain assumptions about the proper analysis of inclusive plurals - in that, I follow Martí 2017, 2020.

Scontras proposes two number features for a language like English: [sG], which triggers singular form and agreement, and [PL], which triggers plural form and agreement. Whereas [SG] comes with a singularity presupposition, [PL] is presupposition-less (from Sauerland 2003); both are identity functions:

$$
\begin{aligned}
& \llbracket \mathrm{SG} \rrbracket=\lambda \mathrm{P}: \forall \mathrm{x} \in \mathrm{P}[\# \mathrm{x}=1] . \mathrm{P} \\
& \llbracket \mathrm{PL} \rrbracket=\lambda \mathrm{P} . \mathrm{P}
\end{aligned}
$$

For Scontras, these features project a \#P (NumberP in Harbour's and my system). For a numeral-less noun phrase, we have (NP is nP in Harbour's and my system):

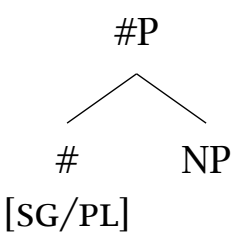

Given Heim's (1991) Maximize Presupposition, it follows that, if the presuppositions of [SG] are met, then [SG] is used; otherwise, [PL] is used.

Additionally, he assumes that an NP like boy denotes a set of atoms. In addition, using Link's 1983 *operator, we can also construct the NP *boy, the set of atoms and non-atoms that are boys:

(41) $\llbracket b o y \rrbracket=\{a, b, c\}$

$\llbracket * b o y \rrbracket=\{a, b, c, a b, b c, a c, a b c\}$

Consider now the four possible combinations of noun semantics and number features in a language of type 1 that arise for Scontras:
a. $\llbracket \mathrm{SG}[\mathrm{NP}$ boy $] \rrbracket=\llbracket\left[{ }_{N P}\right.$ boy $] \rrbracket=\{\mathrm{a}, \mathrm{b}, \mathrm{c}$,
$\rightarrow$ boy

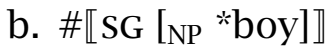
$\rightarrow$ boy
c. $\# \llbracket \mathrm{PL}[\mathrm{NP}$ boy $] \rrbracket=\llbracket[\mathrm{NP}$ boy $] \rrbracket=\{\mathrm{a}, \mathrm{b}, \mathrm{c}\}$
$\rightarrow$ boys
d. $\llbracket \mathrm{PL}[\mathrm{NP} * \mathrm{boy}] \rrbracket=\llbracket\left[{ }_{\mathrm{NP}} * \mathrm{boy}\right] \rrbracket=\{\mathrm{a}, \mathrm{b}, \mathrm{c}, \mathrm{ab}, \mathrm{ac}, \mathrm{bc}, \mathrm{abc}\}$
$\rightarrow$ boys

When combined with [SG], only [NP boy], (42a), gives rise to a well-formed meaning for the noun phrase boy. In (42a), the presupposition of [SG] that every member of the denotation of its input be individuals constituted of 
exactly one atom, or atomic, is satisfied and the meaning of the whole is the same as the meaning of [NP boy], thus giving rise to the correct semantics. In (42b), on the other hand, $\llbracket\left[_{\mathrm{NP}}\right.$ *boy $\rrbracket$ contains both atoms and non-atoms, and so the presupposition of the feature is not met and the result is a presupposition failure. Even though (42b) would have yielded the noun phrase boy, it does not yield a well-formed meaning for it. (42a) does, which also yields the noun phrase boy. The feature [PL], lacking presuppositions, gives

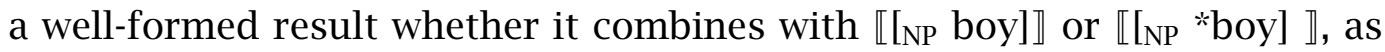
shown in (42c) and (42d), but (42c) is disfavored by Maximize Presupposition, as (42a) delivers the same result but uses an item with a presupposition, the feature [SG]. Thus, (42a) is realized as the noun phrase boy, because of [SG] and the (atomic) semantics of [ $\mathrm{NP}_{\mathrm{N}}$ boy] in (41). (42d) is realized as the noun phrase boys, because of [PL] and the (inclusive) semantics of [NP *boy].

Recall Scontras's assumptions about numerals (section 2.1): they give rise to a syntax in which number features scope over numerals (CARD is repeated in (44)):

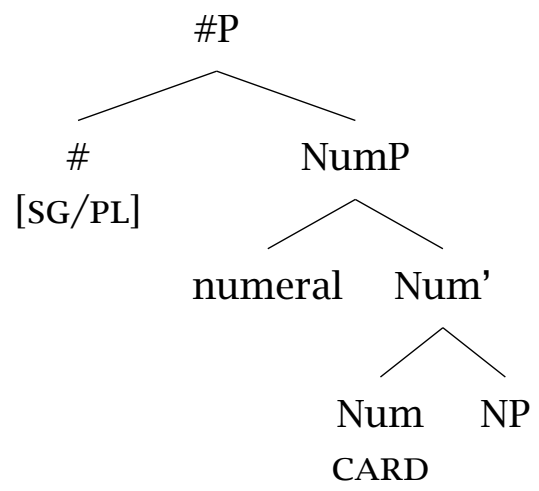

(44) $\llbracket \mathrm{CARD} \rrbracket=\lambda \mathrm{P} \lambda \mathrm{n} \lambda \mathrm{x} \cdot \mathrm{P}(\mathrm{x}) \& \# \mathrm{x}=\mathrm{n}$

The reason why in Scontras's system, two boys is possible but two boy isn't in a type 1 language is as follows. First, CARD may combine with either $\llbracket\left[_{N P}\right.$ boy $] \rrbracket$ or $\llbracket\left[_{N P}\right.$ *boy $\rrbracket$ :

(45) $\quad$ a. $\quad \llbracket C A R D[N P$ boy $] \rrbracket=\lambda \mathrm{n} \lambda \mathrm{x} . \llbracket\left[{ }_{N P}\right.$ boy $] \rrbracket(\mathrm{x}) \& \# \mathrm{x}=\mathrm{n}$

b. $\llbracket$ CARD $[\mathrm{NP} *$ boy $] \rrbracket=\lambda \mathrm{n} \lambda \mathrm{x}$. $\llbracket\left[{ }_{\mathrm{NP}} *\right.$ boy $] \rrbracket(\mathrm{x}) \& \# \mathrm{x}=\mathrm{n}$

Either (45a) or (45b) may then combine with the numeral, though the result is not well-formed for (45a) (there are no members in $\llbracket[N P$ boy]』 constituted of exactly 2 atoms, that is, (46a) denotes the empty set): 
b. $\llbracket$ two CARD $[\mathrm{NP} * \mathrm{boy}] \rrbracket=\lambda \mathrm{x} \cdot \llbracket\left[\left[_{\mathrm{NP}} * \mathrm{boy}\right] \rrbracket(\mathrm{x}) \& \# \mathrm{x}=2\right.$

There are then two possibilities to consider: either (46b) combines with [SG], as in (47a), or it combines with [PL], as in (47b):

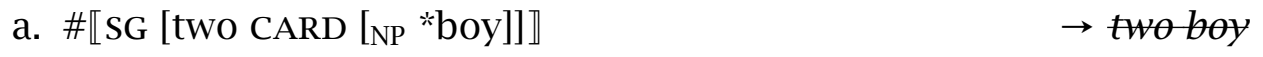

b. $\llbracket \mathrm{PL}[$ two CARD $[\mathrm{NP} * \mathrm{boy}]] \rrbracket=\lambda \mathrm{x} . \llbracket\left[\left[_{\mathrm{NP}} * \mathrm{boy}\right] \rrbracket(\mathrm{x}) \& \# \mathrm{x}=2 \rightarrow\right.$ two boys

(47a) is a presupposition failure, and hence so is two boy, because there are no members in the denotation of its input (in (46b)) constituted of exactly one atom. Only (47b) is well-formed, which correctly gives rise to two boys and to its correct semantics. For one, Scontras appeals to an additional Economy Principle, in (48):

(48) Given two expressions that are denotationally equivalent and where one expression is more complex than the other, choose the simpler expression

(49) provides the two possibilities we have for NumP at this point:

(49) a. $\llbracket$ one CARD $[\mathrm{NP}$ boy $] \rrbracket=\lambda \mathrm{x} . \llbracket\left[{ }_{N P}\right.$ boy $] \rrbracket(\mathrm{x}) \& \# \mathrm{x}=1$

b. $\llbracket$ one CARD $[\mathrm{NP} * \mathrm{boy}] \rrbracket=\lambda \mathrm{x} . \llbracket[\mathrm{NP} * \mathrm{boy}] \rrbracket(\mathrm{x}) \& \# \mathrm{x}=1$

We then have the following four possibilities for \#P:

(50) a. $\llbracket \mathrm{SG}$ [one CARD $[\mathrm{NP}$ boy $]] \rrbracket=\lambda \mathrm{x} . \llbracket\left[{ }_{\mathrm{NP}}\right.$ boy $] \rrbracket(\mathrm{x}) \& \# \mathrm{x}=1 \quad \rightarrow$ one boy

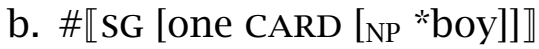
$=\lambda \mathrm{x} \cdot \llbracket\left[\mathrm{NP}_{\mathrm{NP}}\right.$ *boy $] \rrbracket(\mathrm{x}) \& \# \mathrm{x}=1 \quad \rightarrow$ one boy

c. $\# \llbracket$ PL $\left[\right.$ one CARD $\left[{ }_{N P}\right.$ boy $\left.]\right] \rrbracket=\lambda x . \llbracket\left[\left[_{N P}\right.\right.$ boy $] \rrbracket(x) \& \# \mathrm{x}=1 \rightarrow$ one boy

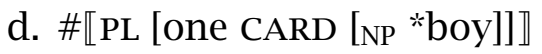
$=\lambda \mathrm{x} . \llbracket[\mathrm{NP} * \mathrm{boy}] \rrbracket(\mathrm{x}) \& \# \mathrm{x}=1$

In (5Oa), the presuppositions of [SG] are satisfied by the denotation of its input, a set of atoms. This means that it, and not (50c), is chosen, and one boy results (with the correct semantics), not one boys. (5ob) is ruled out by the Economy Principle in (48), since it is denotationally equivalent to (50a) but is more complex (since $\llbracket\left[{ }_{N P} * b o y\right] \rrbracket$ is used, and that is more complex than $\llbracket[\mathrm{NP}$ boy $] \rrbracket)$ ((5od) is ruled out by Maximize Presupposition in favour of (5ob), which, as we have seen, is ruled out too). Because there is at least one 
successful derivation for one boy ((50a), not (5ob)), one boy is predicted to be grammatical in English, or, more generally, in languages of type 1, correctly.

For languages of type 2, such as Turkish, Scontras assumes (41), and the same syntax as above. There is a crucial difference, however, in that in Turkish, [SG] is stipulated to be sensitive to relative atomicity, as opposed to English [SG]. Being sensitive to relative atomicity, or P-atomicity, means that what counts as an atom for a predicate $\mathrm{P}$ is relative to what is in $\mathrm{P}$ - for any $\mathrm{P}$, the relative atoms of $\mathrm{P}$ are those members of $\mathrm{P}$ which have no parts in $\mathrm{P}$ :

(51) $\quad \operatorname{card}_{\mathrm{P} \text {-atom }}(\mathrm{x})$ is defined only when $\mathrm{P}(\mathrm{x})=1$. When defined, $\operatorname{card}_{\mathrm{P} \text {-atom }}(\mathrm{x})=|\{\mathrm{y} \in \mathrm{P}: \mathrm{y} \leq \mathrm{x} \& \neg \exists \mathrm{z} \in \mathrm{P} \mathrm{z}<\mathrm{y}\}|$

The cardinality of the set that contains those relative atoms is what Turkish [SG] is sensitive to. The number features assumed for Turkish are in (52), with $\left[\mathrm{SG}_{\mathrm{T}}\right]$ being the singular number feature (I'll speak of $\left[\mathrm{SG}_{\mathrm{E}}\right]$ from now on for English [SG]), and with [PL] still presupposition-less:

$$
\begin{aligned}
& \llbracket \mathrm{SG}_{\mathrm{T}} \rrbracket=\lambda \mathrm{P}: \forall \mathrm{x} \in \mathrm{P}\left[\operatorname{card}_{\mathrm{P} \text {-atom }}(\mathrm{x})=1\right] . \mathrm{P} \\
& \llbracket \mathrm{PL} \rrbracket=\lambda \mathrm{P} . \mathrm{P}
\end{aligned}
$$

For numeral-less phrases, this system gives rise to the following:

$$
\begin{aligned}
& \text { a. } \llbracket \mathrm{SG}_{\mathrm{T}}\left[\mathrm{NP}_{\mathrm{NP}} \text { çocuk }\right] \rrbracket=\llbracket\left[{ }_{\mathrm{NP}} \text { çocuk }\right] \rrbracket=\{\mathrm{a}, \mathrm{b}, \mathrm{c}\} \\
& \rightarrow \text { çocuk }
\end{aligned}
$$

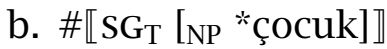

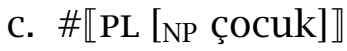

$$
\begin{aligned}
& \rightarrow \text { çocuk } \\
& \text { d. } \llbracket \mathrm{PL}[\mathrm{NP} \text { *çocuk }] \rrbracket=\llbracket\left[{ }_{\mathrm{NP}} \text { *çocuk }\right] \rrbracket \\
& =\{\mathrm{a}, \mathrm{b}, \mathrm{c}, \mathrm{ab}, \mathrm{bc}, \mathrm{ac}, \mathrm{abc}\} \\
& \rightarrow \text { çocuklar } \\
& \rightarrow \text { çocuklar }
\end{aligned}
$$

In (53a), the presupposition of $\left[\mathrm{SG}_{\mathrm{T}}\right]$ is satisfied, since $\llbracket\left[{ }_{\mathrm{NP}}\right.$ çocuk $] \rrbracket$ denotes

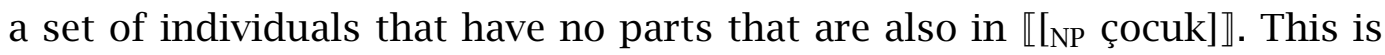
not true in the case of (53b), which is thus a presupposition failure - it is not the case that all members of the sister of $\left[\mathrm{SG}_{\mathrm{T}}\right]$ are P-atoms, since the set contains plural individuals and their parts. (53a) is correctly realized as the noun phrase çocuk and gives rise to the desired, singular semantics. Both (53c) and (53d) satisfy the requirements of [PL], since this feature imposes no requirements. (53c), however, expresses the same meaning as (53a), and (53a) is presuppositional while (53c) is not, so (53c) is not selected. (53d) is correctly realized as the noun phrase çocuklar boys and gives rise to the desired, inclusive semantics. For phrases with a numeral, we have: 


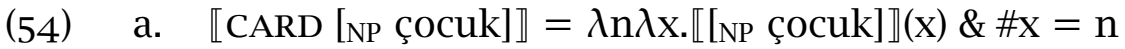

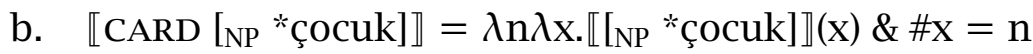

(55) a. \#[iki CARD [NP Çocuk $] \rrbracket$

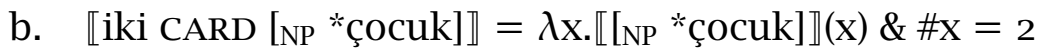

Maximize Presupposition chooses (56a) over (56b), as (56a) is presuppositional and its presuppositions are satisfied, resulting in the correct semantics for iki çocuk 'two boys':

$$
\begin{aligned}
& \text { a. } \llbracket \mathrm{SG}_{\mathrm{T}}[\mathrm{iki} \mathrm{CARD}[\mathrm{NP} \text { *çocuk }]] \rrbracket \\
& =\lambda \mathrm{x} \cdot \llbracket\left[{ }_{\mathrm{NP}}{ }^{*} \operatorname{çocuk}\right] \rrbracket(\mathrm{x}) \& \# \mathrm{x}=2 \quad \rightarrow i k i \text { çocuk } \\
& \text { b. 【PL [iki CARD [NP *çocuk]]】 } \\
& =\lambda \mathrm{x} \cdot \llbracket\left[\mathrm{NP} \text { * }{ }^{2} \mathrm{ocuk}\right] \rrbracket(\mathrm{x}) \& \# \mathrm{x}=2 \quad \rightarrow \text { iki çocuklar }
\end{aligned}
$$

Maximize Presupposition chooses (57a) over (57c) and (57b) over (57d), but (57b) is not selected because of the less complex (57a), as per the Economy Principle in (48). The correct realization and meaning result:

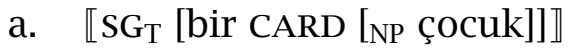
$=\lambda \mathrm{x} \cdot \llbracket[$ NP çocuk $] \rrbracket(\mathrm{x}) \& \# \mathrm{x}=1$
$\rightarrow$ bir çocuk

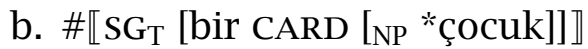
$=\lambda \mathrm{x} \cdot \llbracket[\mathrm{NP} *$ *cocuk $] \rrbracket(\mathrm{x}) \& \# \mathrm{x}=1$
$\rightarrow$ bir çocuk

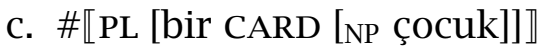
$=\lambda \mathrm{x} \cdot \llbracket[$ NP Çocuk $] \rrbracket(\mathrm{x}) \& \# \mathrm{x}=1$
$\rightarrow$ bir çocuklar
d. $\# \llbracket[$ PL $[$ bir CARD $[\mathrm{NP}$ *çocuk $]] \rrbracket$
$=\lambda \mathrm{x} . \llbracket\left[\right.$ NP ${ }^{*}$ ÇOcuk $] \rrbracket(\mathrm{x}) \& \# \mathrm{x}=1$
$\rightarrow$ bir çocuklar

The account of Turkish bir one and English one combinations is the same, even if $\llbracket \mathrm{SG}_{\mathrm{T}} \rrbracket \neq \llbracket \mathrm{SG}_{\mathrm{E}} \rrbracket$, since with respect to a set of atoms, absolute atomicity and relative atomicity yield the same result (cf. (50) and (57)). Given $\left[\mathrm{SG}_{\mathrm{T}}\right]$, twosomes count as atomic for Turkish iki two (threesomes for üç three, etc.), so nouns are morphologically singular with all numerals ((56)). They do not count as atomic for $\left[\mathrm{SG}_{\mathrm{E}}\right]$.

Scontras's account for languages of types 1 and 2 forms the basis of my analysis in Section 2.2. The same is true for his account of language type 3: the singular feature in this language is ambiguous between $\left[\mathrm{SG}_{\mathrm{T}}\right]$ and $\left[\mathrm{SG}_{\mathrm{E}}\right]$. Western Armenian meg one surfaces in morphologically singular noun phrases because both (50) and (57) yield the same result. When $\left[\mathrm{SG}_{\mathrm{T}}\right]$ is used with yergu two, etc., a morphologically singular noun phrase results ((56)). When, 
instead, $\left[\mathrm{SG}_{\mathrm{E}}\right]$ is used, a morphologically plural noun phrase results ((47)). $\left[\mathrm{SG}_{\mathrm{T}}\right]$ and $\left[\mathrm{SG}_{\mathrm{E}}\right]$ do not compete with each other in Western Armenian, since they are both equally presuppositional. The correct semantics is produced.

To summarize: Scontras proposes a uniform syntax and semantics for all numerals, and for noun phrases, across the three language types. For Scontras, the crucial difference arises in the semantics of the feature [SG], which can vary from one language to another. This is what is responsible for the variation we observe in Table 1.

Notice that the sensitivity of $\left[\mathrm{SG}_{\mathrm{T}}\right]$ to relative atomicity serves no purpose in Scontras's account other than to derive the Turkish and Western Armenian patterns - the feature $\left[\mathrm{SG}_{\mathrm{T}}\right]$ is thus stipulated in this analysis. Ideally, however, there would be independent reasons for adopting it. In the proposal in Section 2.2, on the other hand, the use of Harbour's $(2011,2014)[+$ minimal] feature is motivated independently, in that it serves various purposes other than deriving the patterns in Table 1, and, as we saw in Section 2.2, has the same effect as Scontras's $\left[\mathrm{SG}_{\mathrm{T}}\right]$. Seeing $\left[\mathrm{SG}_{\mathrm{T}}\right]$ as Harbour's $[+$ minimal], we derive the patterns in Table 1 in precisely the principled way that is lacking in Scontras's account. Recall that in the proposal in Section 2.2, numerals in type 2 languages appear in the noun phrases that they do because the theory of grammar assigns those languages a [ \pm minimal] number system.

To see how [+minimal] achieves the same result as Scontras's [ $\left.\mathrm{SG}_{\mathrm{T}}\right]$, consider (56)a again, in (58b), where $\left[\mathrm{SG}_{\mathrm{T}}\right]$ applies to (55a), in (58a), and compare it to the result of applying [+minimal] to (55a), in (58c):

$$
\begin{aligned}
& \text { a. } \llbracket \text { iki CARD }[\mathrm{NP} * \text { çocuk }] \rrbracket=\lambda \mathrm{x} \text {. } \llbracket\left[{ }_{\mathrm{NP}}{ }^{*} \text { çocuk }\right] \rrbracket(\mathrm{x}) \& \# \mathrm{x}=2 \\
& \text { b. } \llbracket \mathrm{SG}_{\mathrm{T}}\left[\mathrm{iki} \mathrm{CARD}\left[\mathrm{NP}{ }^{*} \text { çocuk }\right] \rrbracket=\lambda \mathrm{x} \text {. } \llbracket\left[{ }_{\mathrm{NP}}{ }^{*} \text { çocuk }\right] \rrbracket(\mathrm{x}) \& \# \mathrm{x}=2\right.
\end{aligned}
$$

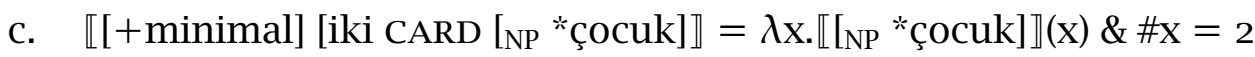

$\left[\mathrm{SG}_{\mathrm{T}}\right]$ checks that the set $\mathrm{P}$ denoted by its argument contains only plural boy individuals with no subparts in P. P contains only plural boy individuals each of which is constituted of exactly 2 atoms, and nothing else, as in (58a), which indeed satisfies $\left[\mathrm{SG}_{\mathrm{T}}\right]$. Thus, NumberP in $(58 \mathrm{a})$, with Scontras's $\left[\mathrm{SG}_{\mathrm{T}}\right]$, is a set of plural boy individuals each of which is constituted of exactly 2 atoms. [+Minimal] is not presuppositional, but it still has the effect that NumberP denotes a set of plural boy individuals each of which is constituted of exactly 2 atoms. In other words, we can replace $\left[\mathrm{SG}_{\mathrm{T}}\right]$ with $[+$ minimal].

However, this result can only be achieved if languages of type 2 are [ \pm minimal] systems - in Harbour's system, if [+minimal] is active in a language, then so is [-minimal]. Important questions arise. What happens with [-minimal] 
in Scontras's analysis, given that there is no difference between [+minimal] and [-minimal] in presuppositional terms? And what about [PL]? More generally, how are plurals, and numeral+noun combinations, derived if languages of type 2 are [ \pm minimal] systems?

As it turns out, there is a basic incompatibility between Sauerland's (2003) view of plurality (and hence Scontras's) and Harbour 2011, 2014: Martí (2017, 2020) shows that embedding a view of plurality like Sauerland's in Harbour's system makes the wrong predictions about the cross-linguistic typology of plurality. Some of the details of her argument are important for us, so I now proceed to summarize it.

Her argument is as follows. First, as is well known (see Farkas \& de Swart 2010, Grimm 2013, Ivlieva 2013, Kiparsky \& Tonhauser 2012, Krifka 1989, 1995, Lasersohn 1995, 2011, Martí 2017, 2020, Mayr 2015, Sauerland 2003, Sauerland, Anderssen \& Yatsushiro 2005, Spector 2007, Yatsushiro, Sauerland \& Alexiadou 2017, Zweig 2009), plural noun phrases in English give rise to either exclusive or inclusive readings. The plurals in (59) are interpreted inclusively: e.g., according to (59a), Lina harvested neither one nor more tomatoes. Denotationally, this means that $\llbracket[$ NumberP tomatoes $] \rrbracket$ should include both singular and plural tomato individuals:
a. Lina didn't harvest tomatoes
b. No students came to the party
c. I don't have children

In upward-entailing contexts, on the other hand, these same phrases are usually interpreted exclusively. If (6oa) is true, for example, Lina needs to have harvested more than one tomato:

\section{(6o) a. Lina harvested tomatoes \\ b. Students came to the party \\ c. I have children}

Two main types of accounts of the distribution of exclusive and inclusive plurals have been pursued. In the first type, plural noun phrases are ambiguous between exclusive and inclusive readings (Farkas \& de Swart 2010, Grimm 2013, Martí 2017, 2020). According to the second type, plural noun phrases are unambiguously inclusive and exclusive readings arise only pragmatically (via implicature, as in Spector 2007, or via Maximize Presupposition, as in Sauerland 2003 and others; these principles are sensitive to the monotonic 
properties of the environment the plural noun phrase finds itself in). I refer to this second type of account as the inclusive-only view of plurality.

As Martí explains, inclusive-only accounts of plurality amount, in Harbour's terms, to the postulation of number systems that deploy [+atomic] (or, possibly, [+minimal])(or a presuppositional version thereof) to the exclusion of [-atomic] (or [-minimal]). Focusing on [+atomic]-only languages, since Martí's argument is based on languages with duals and duals require [ \pm atomic] in principle (recall (25) and (26)), these are languages with singular noun phrases and with inclusive plural noun phrases in downward-entailing contexts, like English. Given Sauerland's pragmatics, based on Maximize Presupposition, exclusive plurals arise via implicature. However, if a number system can deploy [+atomic] without also deploying [-atomic], then it follows that such a number system cannot use [-atomic] elsewhere within the same system. But Harbour argues that [-atomic] is used to derive dual number, as we saw earlier. Martí's argument is that an inclusive-only view of plurality, combined with Harbour's approach to number, predicts that languages with dual number should not have inclusive plurals. This is contrary to fact: Martí shows that languages with both duals and inclusive plurals exist. Thus, either the inclusive-only view of plurality, or Harbour's theory of number, has to be abandoned.

A solution considered by Martí consists in embedding an ambiguity account of plurality within Harbour's system, using Farkas and de Swart's (2010) Strongest Meaning Hypothesis to explain the distribution of exclusive and inclusive plural noun phrases. The availability of inclusive plural noun phrases is due in this proposal to the possibility of not projecting NumberP (that is, having no number features operating on $\mathrm{nP}$ ). Languages like English realize noun phrases where NumberP is not projected as morphologically plural noun phrases. This then derives the number neutrality associated with inclusive plural noun phrases in the right contexts. That is, the availability of exclusive plural noun phrases is due to [-atomic] (recall (13)), and the availability of inclusive plural noun phrases is due to the absence of NumberP as in (61): 
Luisa Martí

(61)

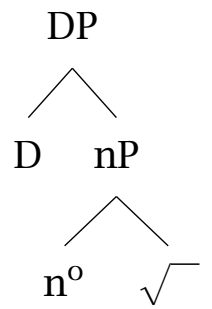

The distribution of the two is regulated by the Strongest Meaning Hypothesis.

Such a solution being the only one that is compatible with Harbour's theory, ${ }^{21}$ and hence with the reduction of Scontras's $\left[\mathrm{SG}_{\mathrm{T}}\right]$ to Harbour's $[+$ minimal] proposed above, a language like English must be a [ \pm atomic] language with the possibility of not projecting NumberP. But this means that [PL] in English cannot be Scontras's [PL] - we cannot maintain an account of plurality that doesn't contain something like [-atomic]. This is the main theoretical motivation for the alternative account of the cross-linguistic patterns in Table 1 I proposed in Section 2.2.

To integrate Martís account of inclusive and exclusive plurality in the account in Section 2.2, all we need to say is that, if a language has inclusive plural noun phrases, then it tolerates the absence of NumberP in numeralless noun phrases and realizes them morphologically as plural. ${ }^{22}$ This will be the case for languages of type 2 as well - if they have inclusive plurals, then they tolerate the absence of NumberP in numeral-less noun phrases; when NumberP is present, exclusive plurals via [-minimal]. ${ }^{23}$

Comparing my account in Section 2.2 to Scontras's, the former takes from the latter the morphosyntactic realization of the notions of atomicity and minimality, the idea that number features operate on phrases that contain

21 For other possibilities, which turn out to be empirically problematic as well, see Martí 2020. 22 Notice that if it is the mere absence of NumberP that prompts the choice of plural forms in these languages, the wrong predictions are made for numeral phrases such as one boys:

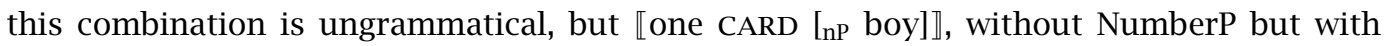
NumeralP, would be assigned the spell out one boys, with the same meaning as one boy. Understanding Martí's statement in such a way that it doesn't apply to phrases with a numeral does not affect her analysis of inclusive plurals.

23 The question arises as to whether Turkish and Western Armenian have inclusive and exclusive plurals. Görgülü (2012) argues that Turkish plural nouns are not inclusive. On the other hand, Sağ (2016: p. 10), 2017 and Renans et al. (2017) argue that they can be. According to Bale, Gagnon \& Khanjian (2011b), Bale \& Khanjian (2014), Western Armenian has exclusive plurals only. I am not able to settle these matters at this point. My proposal in Section 2.2 works whether type 2 or type 3 languages have inclusive plurals or not. 
the numeral, and the idea that this is responsible for the morphological number marking we see on noun phrases in the numeral+noun construction. Importantly, however, my account does not stipulate a special feature for languages of types 2 and 3: the feature that derives these patterns is Harbour's [ \pm minimal]. Because Harbour's [ \pm minimal] is justified independently, as it is the feature that derives, among others, minimal-augmented and singulardual-plural number systems, the work that [ \pm minimal] does here comes for free. Whereas Scontras's account relies on an inclusive-only semantics for plurals, with associated pragmatic principles like Maximize Presupposition, to derive exclusive plurals, my account relies on the features [-minimal] and [-atomic] to derive exclusive plurals, and, following Martí (2017, 2020), on the absence of NumberP, plus a pragmatic principle like the Strongest Meaning Hypothesis, to derive inclusive plurals. Whereas Scontras's account does not suffer from the problem posed by plurals in non-monotone contexts (as in Exactly one of my students has solved difficult problems; see Spector 2007, Farkas \& de Swart 2010: ft. 25), my proposal has no immediate solution to it. Whereas my proposal justifies its tools on the independent grounds provided by Harbour's theory, Scontras's account does not have the tools to derive the typological generalizations in (7).

Finally, both accounts postulate a uniform semantics for numerals, as well as a uniform semantics for the noun phrases involved in the numeral+noun construction, across languages. About the latter, note that the two accounts take the number of the noun phrase of Turkish numeral+noun phrases to be always singular ( $\left[\mathrm{SG}_{\mathrm{T}}\right]$ in Scontras's account, [+minimal] in mine; according to my account, they should thus be more appropriately called minimal, but I stick to the label singular here). Thus, in my account, all Turkish numeral+noun phrases, and all Western Armenian numeral+noun phrases without -ner, contain the NumberP in (62): 
(62)

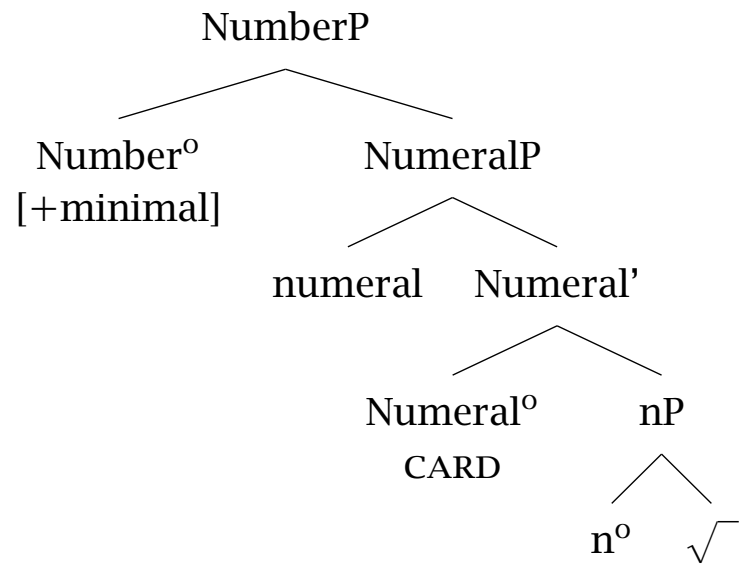

Western Armenian also allows (63) for those cases where the numeral is meg one:

(63)

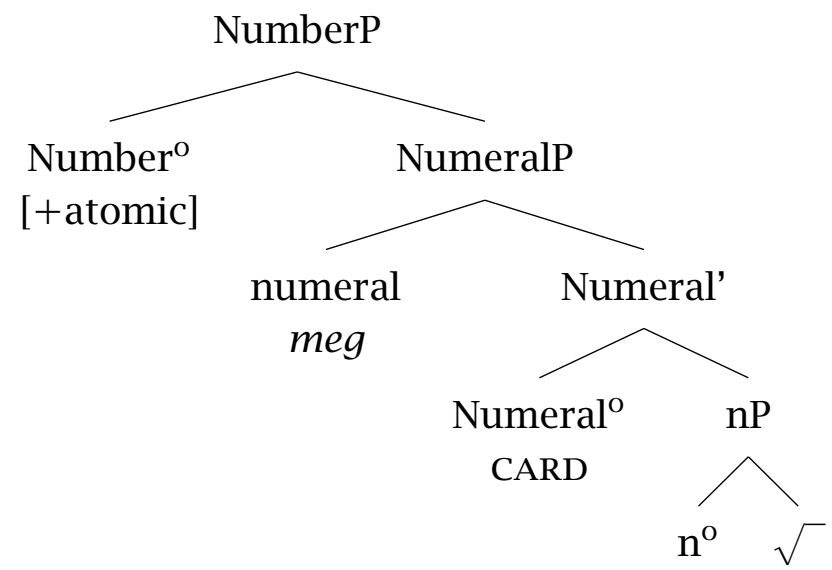

This empirical point is worth making because in Bale, Gagnon and Khanjian's 2011 account, these noun phrases are postulated to be number neutral, not singular. Bale, Gagnon and Khanjian also take the semantics of numerals not to be uniform cross-linguistically. I argue below that both of these assumptions are problematic. 


\section{Bale, Gagnon \& Khanjian $2011 a$}

\subsection{The account}

For Bale, Gagnon \& Khanjian (2011a), there are two possible denotations for numerals: for a numeral like two, that is the subsective semantics in (64), and the intersective semantics in (65):

(64) $\llbracket$ twos $\rrbracket=\lambda \mathrm{P}_{\mathrm{pl}} \cdot\left\{\mathrm{x}: \mathrm{x} \in \mathrm{P}_{\mathrm{pl}} \& \exists \mathrm{Y}(\mathrm{Y} \in \mathrm{PART}(\mathrm{x}) \&|\mathrm{Y}|=2 \& \forall \mathrm{z}(\mathrm{z} \in \mathrm{Y} \rightarrow\right.$ $\left.\left.\left.\mathrm{z} \in \operatorname{MIN}\left(\mathrm{P}_{\mathrm{pl}}\right)\right)\right)\right\}$

(65) $\llbracket \mathrm{two}_{\mathrm{I}} \rrbracket=\{\mathrm{x}: \exists \mathrm{Y}(\mathrm{Y} \in \operatorname{PART}(\mathrm{x}) \&|\mathrm{Y}|=2 \& \forall \mathrm{z}(\mathrm{z} \in \mathrm{Y} \rightarrow \operatorname{ATOM}(\mathrm{z})))\}$

The definitions of $\mathrm{P}_{\mathrm{pl}}$, MIN and ATOM are as follows: ${ }^{24}$

(66) A predicate $\mathrm{P}$ is of type pl iff $\forall \mathrm{x}, \mathrm{y} \in \mathrm{P}(\mathrm{x} \oplus \mathrm{y} \in \mathrm{P})$

(67) $\quad \operatorname{MIN}(\mathrm{P})$ is defined iff $\forall \mathrm{x}, \mathrm{y}((\mathrm{x}, \mathrm{y} \in \mathrm{P} \& \neg \exists \mathrm{z}(\mathrm{z} \in \mathrm{P} \&(\mathrm{z}<\mathrm{y} \vee \mathrm{z}<\mathrm{x}))) \rightarrow \mathrm{x} \wedge \mathrm{y}$ $=\mathrm{o})$. When defined $\mathrm{MIN}(\mathrm{P})=\{\mathrm{x}: \mathrm{x} \in \mathrm{P} \& \neg \exists \mathrm{z}(\mathrm{z}<\mathrm{x})\}$

$$
\operatorname{ATOM}(x)=1 \text { iff } x \in D \& \neg \exists z(z \in D \& z<x)
$$

In (64), the numeral is a function whose input predicate $\mathrm{P}$ is constrained to apply to sets closed under sum formation only (hence, the numeral will not be able to take a set of atoms as its argument) ((66)). It is sensitive to so-called atomic minimal parts - an atomic minimal part of a predicate $\mathrm{P}(\mathrm{MIN}(\mathrm{P}))$ is the smallest possible individual that does not share any parts with other members of $\mathrm{P}((67))$. (64), when combined with a predicate $\mathrm{P}$ of the right type, yields a subset of $\mathrm{P}$, the set that consists of all the individuals that are composed of two individuals that are atomic minimal parts in P. In an intersective semantics like (65), the numeral is a cardinality predicate sensitive to atoms in the domain ((68)). The presence of MIN and ATOM in (64) and (65) foreshadows their role in the accounts discussed earlier, including my account, but here, instead of being independent of the semantics of nu-

24 Bale, Gagnon and Khanjian assume, additionally, (i) and (ii) (see Ionin \& Matushansky 2006, 2018) (aggregates are plural or non-atomic individuals):

(i) $\quad \operatorname{PART}(\mathrm{x})=\{\mathrm{Z}: \mathrm{Z}$ is a partition of $\mathrm{x}\}$

(ii) A partition of an aggregate $\mathrm{x}$ is a set of aggregates $\mathrm{Z}$ such that the join of all the elements in $\mathrm{Z}$ is equal to $\mathrm{x}$ and for any two elements $\mathrm{w}$ and $\mathrm{v}$ in $\mathrm{Z}$, the meet of those two elements is empty 
merals and fully grounded morpho-syntactically, they are part only of their semantic contribution. This prevents the kind of independent justification that both Scontras's and my analysis of the facts seek, and gives rise, as we will see below, to different effects.

Bale, Gagnon and Khanjian are not explicit about the syntax that they assume for noun phrases or the numeral+noun construction, but numerals in their account directly combine with $\mathrm{N}$, without the mediation of number features. I'll assume that the structures in (69) and (70) faithfully represent what they have in mind:

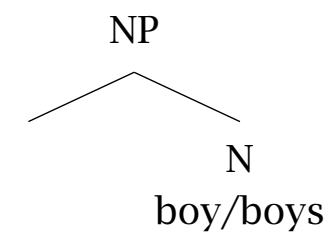

(70)

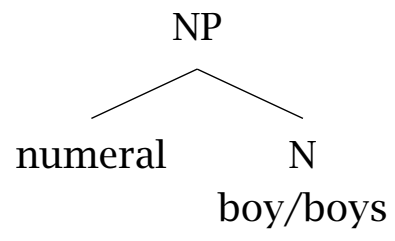

For a language like English, morphologically singular noun phrases are assumed to denote sets of atoms, and plural noun phrases are assumed to denote sets containing atoms plus all the non-atoms that can be formed with them. Thus, assuming a universe with just three boys:

(71) $\llbracket\left[{ }_{\mathrm{N}}\right.$ boy $] \rrbracket=\{\mathrm{a}, \mathrm{b}, \mathrm{c}\}$

(72) $\llbracket\left[{ }_{N}\right.$ boys $] \rrbracket=\{a, b, c, a b, b c, a c, a b c\}$

Numerals greater than one cannot combine with morphologically singular nouns if they have denotations such as (71), whether they are subsective ((64)) or intersective ((65)). Either type of numeral denotation is compatible with morphologically plural nouns $((72))$. As a result, numerals greater than one in English combine only with plural nouns.

Turkish uses a different semantics for morphologically singular and plural nouns in this account:

(73) $\llbracket[\mathrm{N}$ çocuk $] \rrbracket=\{\mathrm{a}, \mathrm{b}, \mathrm{c}, \mathrm{ab}, \mathrm{bc}, \mathrm{ac}, \mathrm{abc}\}$

(74) $\llbracket\left[\left[_{N}\right.\right.$ çocuklar $] \rrbracket=\{a b, b c, a c, a b c\}$ 
Additionally, numerals greater than one are assumed to have only a subsective semantics in this language. As a result, numerals can only combine with morphologically singular nouns in this language:
a. $\llbracket$ iki $_{\mathrm{S}}[\mathrm{N}$ çocuk $] \rrbracket$ $=\{\mathrm{x}: \mathrm{x} \in \llbracket[\mathrm{N}$ çocuk $] \rrbracket \& \exists \mathrm{Y}(\mathrm{Y} \in \mathrm{PART}(\mathrm{x}) \&|\mathrm{Y}|=2$ and $\forall \mathrm{z}(\mathrm{z} \in \mathrm{Y} \rightarrow$ $\mathrm{z} \in \operatorname{MIN}(\llbracket[\mathrm{N}$ çocuk $] \rrbracket)))\}$
$\rightarrow$ iki çocuk

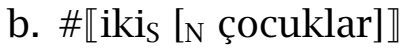
$\rightarrow$ ikiçocuklar

Given (73) and (74), a subsective semantics for numerals greater than one gives a different result from English. The combination of such numerals with morphologically singular nouns is predicted to be grammatical, and with the desired semantics, as in (75a) (for iki 'two'). Their combination with morphologically plural nouns, (75b), is predicted to be a presupposition failure, since it is not possible to satisfy MIN ((74)): there are no atomic minimal parts in (74), since the smallest elements in that predicate overlap. The assumption is that this presupposition failure is responsible for the ungrammaticality of *iki çocuklar.

As for Western Armenian, its noun semantics is proposed to be like that in Turkish, but its numerals are always intersective:

a. $\llbracket \operatorname{yergu}_{\mathrm{I}}\left[_{\mathrm{N}}\right.$ dəgha $] \rrbracket$ $=\{\mathrm{X}: \exists \mathrm{Y}(\mathrm{Y} \in \mathrm{PART}(\mathrm{x}) \&|\mathrm{Y}|=2$ $\& \forall \mathrm{z}(\mathrm{z} \in \mathrm{Y} \rightarrow \operatorname{ATOM}(\mathrm{z}))) \& \llbracket\left[\left[_{\mathrm{N}}\right.\right.$ dəgha $] \rrbracket(\mathrm{x})$ $\rightarrow$ yergu dəgha

b. $\quad$ yergu [N $_{\mathrm{N}}$ dəghaner $\rrbracket \rrbracket$ $=\{\mathrm{x}: \exists \mathrm{Y}(\mathrm{Y} \in \mathrm{PART}(\mathrm{x}) \&|\mathrm{Y}|=2$ $\& \forall \mathrm{z}(\mathrm{z} \in \mathrm{Y} \rightarrow \mathrm{ATOM}(\mathrm{z}))) \& \llbracket\left[{ }_{\mathrm{N}}\right.$ dəghaner $] \rrbracket(\mathrm{x}) \quad \rightarrow$ yergu dəghaner

The intersective semantics of $\operatorname{yergu}_{I}$ 'two' does not impose constraints on the denotation of the noun it combines with, and there is no sensitivity to atomic minimal parts. Thus, both (76a), yergu dəgha 'two boy' and (76b), yergu dəghaner 'two boys' are grammatical and have the desired semantics. ${ }^{25}$

Thus, according to Bale, Gagnon and Khanjian, $\mathrm{N}$ varies in its denotation from one language to another (English vs. Turkish/Western Armenian), as does the semantics of numerals (subsective in Turkish, intersective in West-

25 Bale, Gagnon and Khanjian do not discuss the semantics of the numeral one in any of the three languages, which never combines with morphologically plural nouns, as we know. Depending on how one accounts for its semantics, there may be further issues with this proposal, but I do not discuss them here. 
ern Armenian, possibly both in English). However, there is no independent empirical evidence that the semantics of numerals should vary in this way across the three language types (or more generally) - the null hypothesis is that it is the same across languages, as in both Scontras's and my account. On this count, Bale, Gagnon and Khanjian's proposal is quite unappealing.

Whether the semantics of $\mathrm{N}$ should vary from one language to another is also an empirical question, and here Bale, Gagnon and Khanjian do provide an empirical argument that morphologically singular Ns in Turkish and Western Armenian are number-neutral, based on their semantic behavior when used as bare noun phrases (i.e., without a numeral, a D, a quantifier, etc.). It is to this argument that we turn below. I show that Bale, Gagnon and Khanjian's assumptions about Turkish and Western Armenian morphologically singular Ns are not empirically justified.

For comparison, recall that morphologically singular bare noun phrases in my and Scontras's account are semantically singular in the three types of languages (because they use $\left[\mathrm{SG}_{\mathrm{E}}\right] /\left[\mathrm{SG}_{\mathrm{T}}\right]$ in Scontras's account, [+atomic]/ [+minimal] in mine). Recall numerals/CARD always combine with numberneutral nPs in my account, but in this account number is a property of full noun phrases, not of subparts of them, such as nPs - what is descriptively known as bare nouns or bare noun phrases are not nPs but at least NumberPs, and possibly DPs.

\subsection{The semantics of morphologically singular noun phrases in Turkish and Western Armenian}

Bale, Gagnon \& Khanjian (2011a) assume that morphologically singular Ns in the numeral+noun construction in Turkish and Western Armenian are semantically number-neutral because they give rise to a number-neutral semantics when used without the numeral. Following Sağ $(2016,2017)$ and Martí (2017), I argue that this assumption is not empirically justified. As we will see, Turkish morphologically singular bare nouns are number-neutral only when incorporated, that is, in non-argumental positions. Crucially, morphologically singular bare noun phrases are semantically singular in nonincorporated, argumental positions - and there are no reasons to think that incorporation is involved in the numeral+noun construction. In Western Armenian, morphologically singular bare noun phrases are either singular count noun phrases or naturally atomic mass noun phrases (in the sense of Bale \& Barner 2009, Landman 2011, Rothstein 2010a,b, among others), but, crucially, 
numerals appear in the former, not in the latter. Thus, in addition to the theoretical shortcomings of this proposal, discussed in Section 4.1, there are empirical shortcomings as well.

\subsubsection{Turkish singular noun phrase semantics}

Morphologically singular bare noun phrases in Turkish are usually taken to be number neutral semantically (Acquaviva 2005, Bale, Gagnon \& Khanjian 2011a, Bliss 2004, Corbett 2000, Göksel \& Kerslake 2005, Görgülü 2012, Walter 2014). Consider the following examples, often discussed in this literature:

(77) Turkish

Kitap al-dı-m

book buy-PAST-1SG

'I bought a book/books'

(78) Turkish

Ali-yi arı sok-tu

Ali-ACC bee sting-PAST

'Bees stung Ali'/'Ali got bee-stung'

(79) Turkish

Çocuk gel-miş

child come-Evid

'There was one or more children coming'

In (77)-(79), the highlighted noun phrases receive a number neutral interpretation, as can be seen from the translations. One reason why that might be is that, as hypothesized in Bale, Gagnon and Khanjian, the noun phrases in these sentences have a number neutral denotation. However, as discussed in Cabredo Hofherr 2021 and references cited there, number neutrality can have sources other than noun phrase semantics. In particular, Sağ $(2016,2017)$ and Martí (2017) show that the number neutrality observed in (77)-(79) depends on the incorporation of the relevant noun to the verb - it disappears when the noun is not incorporated. It is thus likely that the source of the number neutrality in (77)-(79) is due to the semantics of incorporation (see Carlson 2006 and Dayal 2015 for overviews on the semantics of incorporation). In turn, this calls into question a number-neutral semantics for $\mathrm{N}$ in the numeral+noun construction in Turkish. 
To see the problem, consider that lack of incorporation in Turkish is recognizable from Case marking, syntactic position and intonation, as argued for by Öztürk (2009) (see also Kan 2010). ${ }^{26}$ Importantly, as Sağ and Martí note, when incorporation does not occur, i.e., when the noun phrases in question are forced into argument positions, morphologically singular bare noun phrases in Turkish are no longer number neutral but singular. For example, consider (80), a minimal pair for (77):

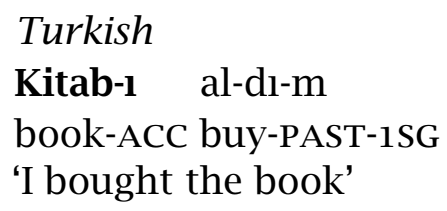

Accusative Case marking in Turkish induces definiteness effects, as is well known (Enç 1991, von Heusinger \& Kornfilt 2005, among others). But adding it to (77), as in (80), has two effects, not one: the definiteness of the noun, and, more importantly, its unambiguous singular interpretation. The latter effect is fully expected if noun incorporation in Turkish is blocked when the noun is Case marked. Lack of adjacency between the noun and the verb $((81))$ and stress on the verb ((82)) (in (79), stress is on çocuk) also block incorporation, and, again, a singular interpretation is the only possibility in these cases:

Turkish

Arı Ali-yi sok-tu

bee Ali-ACC sting-PAST

'The bee stung Ali'

(82) Turkish

Çocuk gel-miş

child come-EVID

'The child came'

Thus, when the conditions for incorporation are not met, singular (definite) interpretations arise in Turkish, which suggests that the number neutrality

26 See Knecht 1986 and Mithun 1984 for more on Turkish incorporation. Öztürk (2009), building on Massam 2001 and Dayal 2011, argues that the appropriate label for Turkish is pseudoincorporation, since the relationship between the noun and the verb is less constrained in Turkish than in traditional incorporating languages. This difference doesn't play a role in my argument below. 
of examples in (77)-(79) is not due to the semantics of $\mathrm{N}$, but to the semantics of incorporation.

Note that the above singular interpretations cannot be brought about by Case, the syntactic position of the noun phrase or intonation themselves, since plural noun phrases, as shown by Ketrez (2003), get semantically plural readings in these cases. For example, in (83), with Accusative Case marking on the noun and with stress on the verb, the noun phrase is interpreted as plural, not singular: ${ }^{27}$

(83) Turkish

Ayşe kitap-lar-ı oku-du

Ayşe book-PL-ACC read-PAST

'Ayşe read the books'

The discussion above establishes that there is a semantic distinction in Turkish between morphologically singular bare noun phrases in argument positions vs. noun phrases in non-argument positions. The next question is whether nouns in the numeral+noun construction in Turkish are incorporated or not. To maintain Bale, Gagnon and Khanjian's hypothesis that numerals combine with number-neutral Ns in this construction, it would have to be the case that such nouns incorporate into the numeral. The main problem with this idea is that, as it currently stands, it would serve no purpose other than to facilitate the analysis of Turkish envisaged by these authors. We know that numerals may be syntactic heads, taking the noun (or a projection of the noun) as complement (Borer 2005, Cardinaletti \& Giusti 2006, Danon 2012, Giusti 1997, Ionin \& Matushansky 2006, 2018 Longobardi 2001, Shlonsky 2004, Danon 2012), or phrases, which function as specifiers (Cinque 2005, Corver \& Zwarts 2006, Danon 2012, Franks 1994, Giusti 1997, 2002, Kayne 2010, among others), and there are other distinctions and patterns that the rich literature on numerals and the numeral+noun construction recognizes,

27 In addition to individual plurality, exemplified in (83) and accounted for above, -lAr can give rise to event plurality types/kinds plurality (Ketrez 2003). That the plural marker can give rise to additional readings might call into question the proposal that Turkish is a singularplural number system (minimal-augmented in my analysis above). But event or type/kind plurality cannot be the source of individual plurality, since individual plurality is available in (83), but the other two readings aren't. Thus, an account of individual plurality is necessary that is independent of other types of plurality. $-L A r$ can also be a marker of associative plurality (Lewis 1967, Sebüktekin 1971, Göksel \& Kerslake 2005, Görgülü 2011); Görgülü (2011) argues that this is also a separate use. Cf. also footnote 9. 
but there isn't one that would independently justify an incorporation relationship between numerals and nouns.

Importantly, if Turkish morphologically singular bare noun phrases are in fact not number neutral semantically, the account of Turkish defended in Bale, Gagnon and Khanjian is no longer empirically justified, a point made also in Sağ 2016, 2017. In particular, the subsective denotation of iki ((64)) no longer combines with that of the $\mathrm{N}$ çocuk in (84), since it is no longer the case that the denotation of its input argument is closed under sum formation:

(84) $\llbracket\left[{ }_{\mathrm{N}}\right.$ çocuk $] \rrbracket=\{\mathrm{a}, \mathrm{b}, \mathrm{c}\}$

An intersective semantics would not work either, since (65) does not felicitously combine with (84). ${ }^{28}$

The evidence above suggests that the treatment of unincorporated, morphologically singular bare noun phrases in my account in Section 2.2 (and in Scontras's account) is correct. To repeat: I've proposed that a noun phrase like kitab-ı book in (80) is analyzed as containing (85) as part of its structure, that is, as a semantically singular noun phrase (ignoring Case and other irrelevant matters):

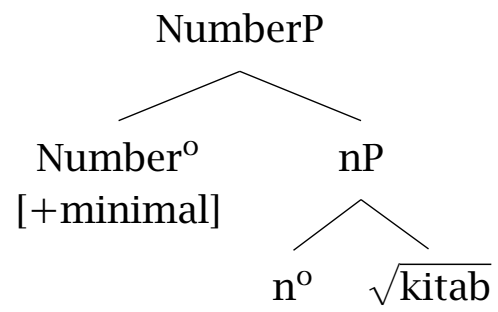

$\lambda \mathrm{x} . \llbracket[\mathrm{nP}$ kitab] $\rrbracket(\mathrm{x}) \& \neg \exists \mathrm{y}$

$\llbracket[$ nP kitab] $\rrbracket(y) \& y \sqsubset x=$

$\{\mathrm{a}, \mathrm{b}, \mathrm{c}\}$

That is, nouns such as kitab 'book', when unincorporated, form [+minimal] noun phrases. I've also proposed that $[+$ minimal] is present in noun phrases that contain a numeral as well (cf. (35), (36e) and (36g)):

28 Sağ $(2016,2017)$ argues for the privative numeral semantics of Ionin \& Matushansky (2006, 2018). In their proposal, numerals combine with semantically singular nouns to return sets of pluralities. Bale, Gagnon and Khanjian argue against this semantics on the basis of their understanding of the denotation of morphologically singular nouns in Turkish (recall from Section 4.1 that they take them to be number-neutral semantically across the board), which we have just seen is not justified. From the perspective of the proposal defended here, in this kind of analysis it remains unclear whether or how the typology in Table 1 could be accounted for in the general, principled way it seeks (but see Ionin \& Matushansky 2018 for more). 
(86)

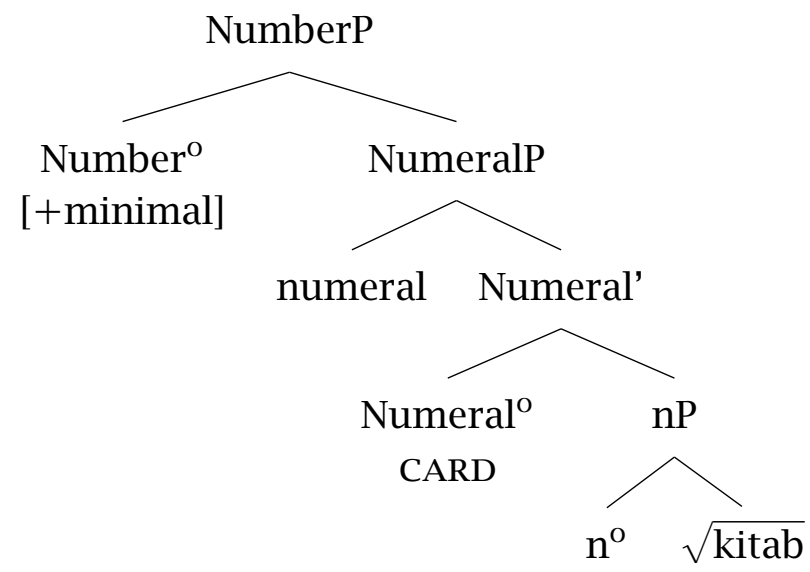

Notice that, while NumeralP combines with $\mathrm{nP}$, which is semantically number-neutral, in (86), the grammatical number of the phrase is [+minimal], that is, singular. This is different from saying that the numeral combines with number-neutral nouns in Turkish: in the present account, the 'noun' is both NumberP and nP, so it is indeed both semantically and morphologically singular in (86). ${ }^{29}$

\subsubsection{Western Armenian singular noun semantics}

Western Armenian morphologically singular bare noun phrases are plausibly analyzed as naturally atomic mass (in the sense of Bale \& Barner 2009, Landman 2011, Rothstein 201ob,a, among others) in examples such as (87)-(88): ${ }^{30}$

(87) Western Armenian

Maro-n tuz g-ude

Maro-DEF fig IMP-eat.3SG

'Maro eats one or more figs'

Western Armenian

Зеваn-e-n jif ing-av

table-ABL-DEF bottle fall.AOR-3SG

'From the table one or more bottles fell'

29 One possible analysis for incorporated nouns is that they project at most nP, which would give rise to number neutrality. See Carlson 2006 and Dayal 2015 for more on the semantics of incorporation.

30 Western Armenian examples are from Sigler (1997) and have been corroborated by Hossep Dolatian. 
A naturally atomic mass interpretation is a number-neutral interpretation, as shown in more detail below, compatible with both Bale, Gagnon \& Khanjian 2011a and the interpretation these examples receive. However, I argue below that this cannot be how they are interpreted in the numeral+noun construction. ${ }^{31}$

A plausible explanation for the number-neutral interpretations in (87)(88) is that morphologically singular noun phrases like fif 'bottle' or tuz 'fig' are indeed mass, as argued for by Bale \& Khanjian (2008) and Sigler (1997), more specifically, mass nouns with naturally atomic parts, like luggage, furniture, or mail in English (Bale \& Barner 2009, Landman 2011, Rothstein 2010a,b, among others; for Sigler, they are typical mass nouns like English water). If these bare noun phrases are naturally atomic mass, then their number-neutral interpretation is like that of nouns such as furniture or luggage:

(89) I bought furniture for the living room

(9o) I carried luggage up the stairs

According to (89), I bought one or more pieces of furniture, and according to (90), I carried one or more pieces of luggage upstairs. These noun phrases indeed allow for a cumulative interpretation in Western Armenian, as shown by (91), which makes them compatible with a mass denotation (cf. Link 1983):

(91) Maro-n ator kənets, jes ator kənets-i, menk ator Maro-DEF chair buy.PAST, I chair buy.PAST-1SG, we chair kənets-ink buy.PAST-1PL 'Maro bought a chair, I bought a chair, we bought a chair'

The question is whether nouns in noun phrases with numerals are also naturally atomic mass in Western Armenian - my account in Section 2.2 (and Scontras's) takes them to be [+minimal]/[+atomic] noun phrases instead, so semantically singular. Importantly, naturally atomic mass nouns, like typical mass nouns, cannot combine directly with numerals, in English or in other languages (cf. English *three water, *three luggage; Brazilian Portuguese *tres menino, tres meninos, Cilene Rodrigues, p.c.). While I haven't been able to find clear cases of naturally atomic mass nouns in Western Armenian, typical

31 Incorporation cannot be the source of number neutrality in (87)-(88), since Western Armenian does not have noun incorporation (Sigler 1997: pp. 71-88). 
mass nouns do not combine directly with numerals in this language (Khanjian 2012):

(92) Western Armenian

*Jerek \{kini| vosgi| alujr $\}$

three wine gold flour

(cf. Hisun gram alujr, lit. 'fifty gram flour', 'fifty grams of flour')

We must then assume that the Western Armenian morphologically singular nouns in examples such as (6), repeated as (93), appear here in a second, count denotation: ${ }^{32}$

(93) Western Armenian

Yergu \{dəgha| dəgha-ner\}

two boy.SG boy-PL

'Two boys'

32 Western Armenian has a classifier (Borer 2005, Khanjian 2012, Sigler 2003), preferred by some speakers in (93):

(i) Western Armenian

Yergu (had) \{dəgha| dəgha-ner\}

two CLASS boy.SG boy-PL

'Two boys'

For some, but not all, speakers, had is impossible with morphologically plural nouns. Had cannot occur with (typical) mass nouns. Turkish is also claimed to have a classifier; see Sağ 2016, 2017. 
This second, count denotation is systematically available for morphologically singular nouns, as when a definite article is added to our earlier examples, only a semantically singular interpretation arises: ${ }^{33,34,35}$

33 This interpretation is not due to the definite article itself, given (i), with plural tuz-er-ə 'figs':

(i) Western Armenian

Maro-n tuz-er-ə g-ude

Maro-DEF fig-PL-DEF IMP-eat.3SG

'Maro eats the figs'

34 Sigler (1997) argues that dəgha is a (typical) mass noun in (93). Both her and Donabédian (1993) show that there is a difference in interpretation between the singular and the plural noun in the numeral+noun construction: with yergu dəgha, "the speaker is not interested in the individual [boys], but in the number and type of person", whereas with yergu dəghaner, "the speaker is interested in the [boys] individually" (Sigler 1997: p. 41, pp. 146-150). The difference is illustrated in (i) and (ii) (due to Hossep Dolatian):

(i) Western Armenian

(number context)

A: A lot of people are walking on this street today

B: Ajo dzifd es ajsor yergu \{artfig ants-avl artfig-ner

yes right be.2SG today two girl pass.by-PAST.3SG girl-PL

ants-an\}

pass.by-PAST.3PL

'Yes, that's true. Two girls passed by today'

(ii) Western Armenian

(identity context)

A: Who stole my apple?

B: Jes desa ov orav yergu \{\#artfig koxts-av| artfig-ner koxts-an\}

I see.PAST who did two girl steal-PAST.3SG girl-PL steal-PAST.3PL

xəntsor-ə

apple-DEF

'I saw who did it. Two girls stole the apple'

For Sigler (cf. Donabédian), the source of the difference between (i) and (ii) is that dəgha, being (typical) mass, does not allow differentiation among subparts of the boy-mass; being count, dəghaner does, which entails identification. However, given that neither naturally atomic mass nouns, nor typical mass nouns, combine directly with numerals, as pointed out in the text, Sigler's analysis cannot be maintained. The difference between (i) and (ii) must then be rooted elsewhere (e.g., identifiability may be introduced by something else higher in the structure; cf. Russian koe- indefinite determiners, which require speaker identifiability, see Martí \& Ionin 2019 and references cited there). It remains to be seen what the best analysis of naturally atomic mass nouns in Western Armenian is.

35 The only remaining facts which remain to account for are the predicative uses of morphologically singular nouns in these languages, which Bale, Gagnon \& Khanjian (2011a) argue also point to a number-neutral semantics. Given the reasoning in the text, we must ask whether 
(94) Western Armenian

Maro-n tuz-o g-ude

Maro-DEF fig-DEF IMP-eat.3SG

'Maro eats the fig'

(95) Western Armenian

Sеваn-e-n fif-ə ing-av

table-ABL-DEF bottle-DEF fall.AOR-3SG

'From the table the bottle fell'

Going back to my account in Section 2.2, my proposal is that Western Armenian uses either (96) or (97) as part of the structure of morphologically singular bare count noun phrases, and (98) or (99) as part of the structure for noun phrases with a numeral like yergu two (recall that, since [-atomic] in Western Armenian is assumed to be spelled out as -ner, (99) gives rise to yergu dəgha-ner 'two boys'):

(96)

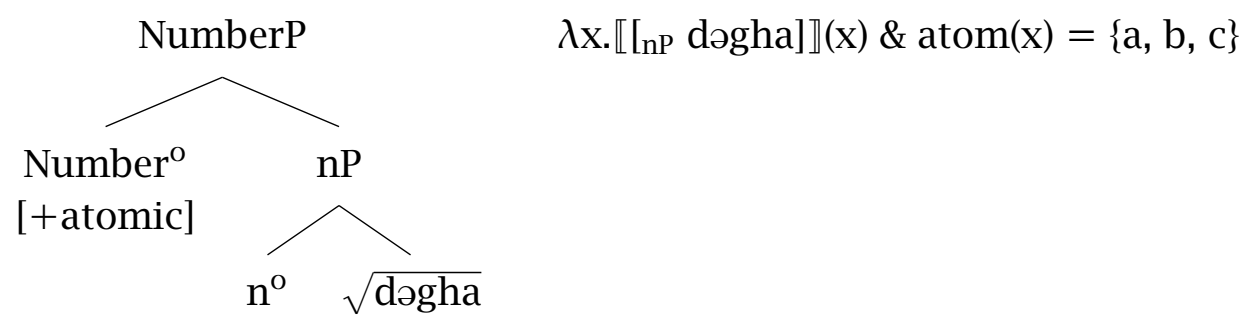

(97)

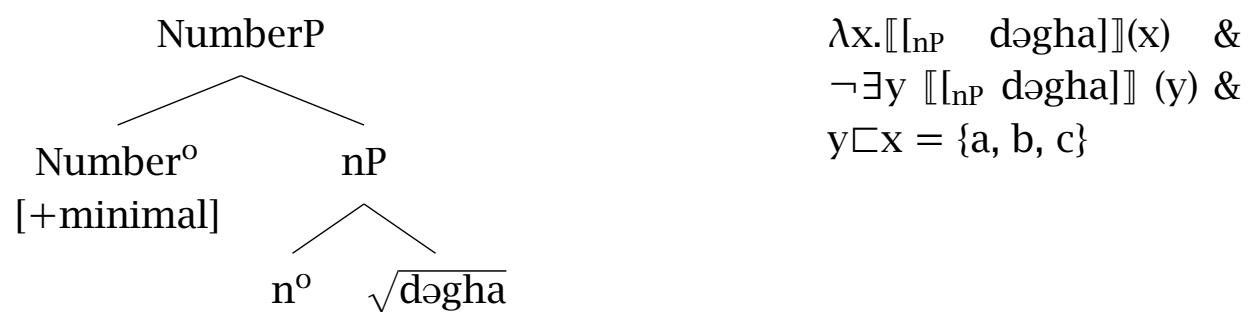

predicative positions are argumental positions (see Williams 1983 and much subsequent literature). An analysis involving a distributivity operator seems plausible, which Bale, Gagnon and Khanjian do not exclude (p. 588, ft. 5). 
(98)

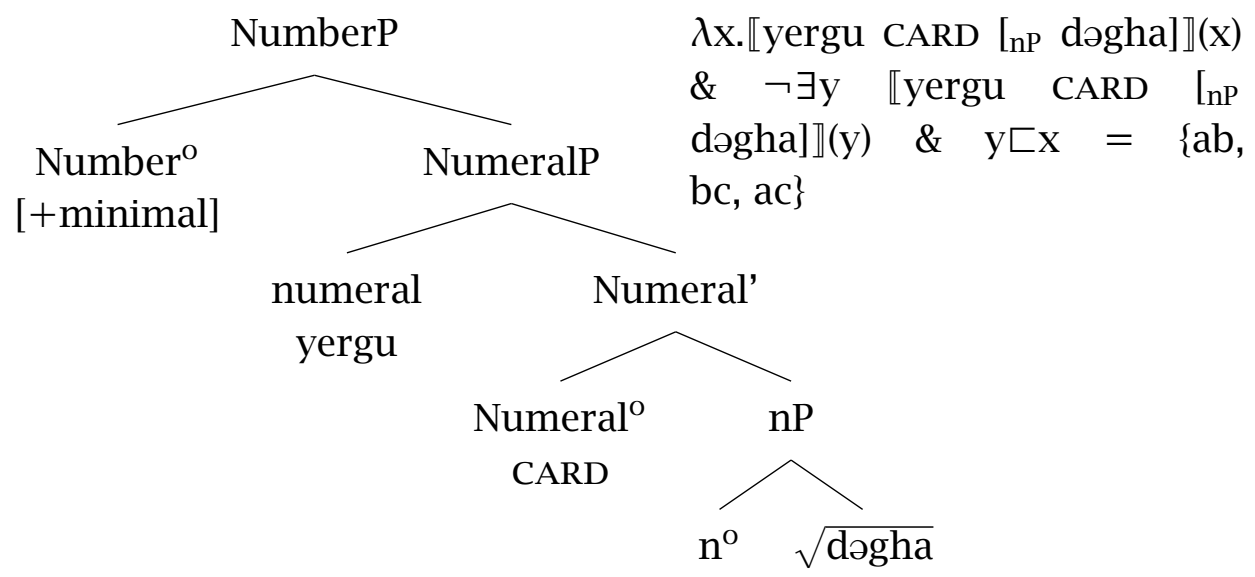

(99)

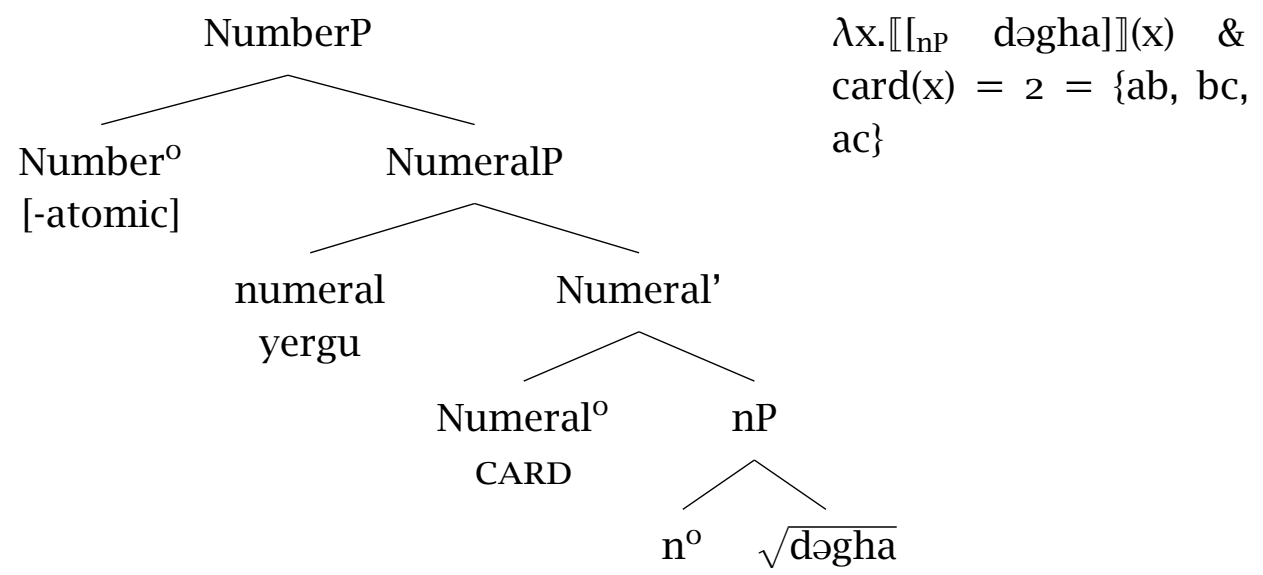

These proposals are compatible with the evidence we have reviewed in this section.

To summarize: Bale, Gagnon \& Khanjian (2011a) propose that the differences in Table 1 follow in part from morphologically singular bare noun phrases in English being semantically singular while semantically number neutral in Turkish and Western Armenian. I have argued, however, that morphologically singular bare noun phrases in argument position in Turkish are interpreted as semantically singular only. In Western Armenian, morphologically singular nouns are semantically singular in the numeral+noun construction. Bale, Gagnon and Khanjian's assumptions are thus not only theoretically unappealing, but empirically unsubstantiated as well. 


\section{Conclusion}

In this paper I have argued for an analysis of the cross-linguistic patterns in Table 1 based on the system in Scontras 2014, but with the following developments: (a) a single, number-neutral semantics for $\mathrm{nP}$ for all languages, as in Harbour 2011, 2014, (b) a non-arbitrary appeal to $\left[\mathrm{SG}_{\mathrm{T}}\right]$ in the form of Harbour's [+minimal], so that what was expressed as a stipulation before is now derived from the theory of number, and (c) a Harbour-compatible understanding of inclusive and exclusive plurality, facilitated by the adoption of Martí (2017, 2020). My account achieves this while maintaining the appeal of Scontras's system, including his uniform interpretation for numerals across languages, and the correct treatment of bare noun phrases in Turkish and Western Armenian, which was shown to be problematic for Bale, Gagnon \& Khanjian (2011a). I hypothesized type 1 languages to be [ \pm atomic] number systems, type 2 languages to be [ \pm minimal] number systems, and type 3 languages to have both [ \pm atomic] and $[ \pm$ minimal] number systems:

\begin{tabular}{|c|c|c|c|c|c|}
\hline & \multicolumn{2}{|c|}{ [士atomic] } & \multicolumn{2}{|c|}{$[ \pm$ minimal $]$} & $\begin{array}{l}{[ \pm \text { atomic }] /} \\
{[ \pm \text { minimal }]}\end{array}$ \\
\hline One $N$ & $\begin{array}{l}\text { singular } \\
\text { phrase }\end{array}$ & noun & $\begin{array}{l}\text { singular } \\
\text { phrase }\end{array}$ & noun & $\begin{array}{l}\text { singular noun } \\
\text { phrase }\end{array}$ \\
\hline Two, etc. $N$ & $\begin{array}{l}\text { plural } \\
\text { phrase }\end{array}$ & noun & $\begin{array}{l}\text { singular } \\
\text { phrase }\end{array}$ & noun & $\begin{array}{l}\text { singular/plural } \\
\text { noun phrase }\end{array}$ \\
\hline Languages & \multicolumn{2}{|c|}{$\begin{array}{l}\text { English, Spanish, } \\
\text { German }\end{array}$} & \multicolumn{2}{|c|}{$\begin{array}{l}\text { Hungarian, } \\
\text { Turkish, Finnish }\end{array}$} & $\begin{array}{l}\text { Western Arme- } \\
\text { nian, Miya, Itzaj } \\
\text { Maya }\end{array}$ \\
\hline
\end{tabular}

Table 6 The three language types, according to their number system

Thus, the only element of variation in this approach is the type(s) of grammatical number system each language has access to - with grammatical number systems regulated by the principles of Harbour's theory of number. In the account presented here, numerals greater than one appear in morphologically plural noun phrases in English because the members of a set of non-atoms are not atoms, and such a set can be characterized by [-atomic] (which spells out as $-s$ in English). Such numerals, on the other hand, appear in morphologically singular noun phrases in Turkish because individuals in 
a set of non-atoms also count as having no subparts in the set, and such a set can be characterized by [+minimal] (which spells out as $\varnothing$ in Turkish). The individuals in a set of atoms, on the other hand, are both atoms ([+atomic]) and have no subparts in the set ([+minimal]), so the difference between Turkish and English is obliterated in the single case of the numeral one, correctly. From the perspective of Harbour (2011, 2014, 2016), the paper demonstrates that the numeral+noun construction is another domain where [ \pm atomic] and [ \pm minimal] may be teased apart. From the perspective of Scontras (2014), the paper demonstrates that the structure of the explanation of the patterns in Table 1 requires neither an inclusive-only view of plurality nor the stipulation of a number feature like $\left[\mathrm{SG}_{\mathrm{T}}\right]$. All in all, the paper explores the benefits of the full morphosyntactic grounding of the semantic notions of atomicity and minimality, including their embedding in a full-fledged featural theory like Harbour's - the most important benefit is the independent justification of the tools needed in the account of the numeral+noun construction that such a move affords.

\section{References}

Acquaviva, Paolo. 2005. The morphosemantics of transnumeral nouns. Morphology and Linguistic Typology: Mediterranean Morphology Meeting (MMM) 4 .

Alexiadou, Artemis. 2019. Morphological and semantic markedness revisited: The realization of plurality across languages. Zeitschrift für Sprachwissenschaft 38. 123-154. https://doi.org/10.1515/zfs-2019-0004.

Bale, Alan \& David Barner. 2009. The interpretation of functional heads: Using comparatives to explore the mass/count distinction. Journal of Semantics 26(3). 217-252. https://doi.org/10.1093/jos/ffpoo3.

Bale, Alan \& Jessica Coon. 2014. Classifiers are for numerals, not for nouns: Consequences for the mass/count distinction. Linguistic Inquiry 45(4). 695-707. https://doi.org/10.1162/ling_a_00170.

Bale, Alan, Michaël Gagnon \& Hrayr Khanjian. 2011a. Cross-linguistic representations of numerals and number marking. Semantics and Linguistic Theory (SALT) 20. 582-598. https://doi.org/10.3765/salt.v20io.2552.

Bale, Alan, Michaël Gagnon \& Hrayr Khanjian. 2011b. On the relationship between morphological and semantic markedness: The case of plural morphology. Morphology 21. 197-221. https://doi.org/10.1007/s11525-010-9 158-1. 
Bale, Alan \& Hrayr Khanjian. 2008. Classifiers and number marking. Semantics and Linguistic Theory (SALT) 18. 73-89. https://doi.org/10.3765/salt .v18io.2478.

Bale, Alan \& Hrayr Khanjian. 2014. Syntactic complexity and competition: The singular-plural distinction in Western Armenian. Linguistic Inquiry 45(1). 1-26. https://doi.org/10.1162/LING_a_oo147.

Biggs, Bruce G. 1975. A Mele-Fila vocabulary (Te Reo Monographs). Auckland: Linguistic Society of New Zealand.

Bliss, Heather. 2004. The semantics of the bare noun in Turkish. Calgary Papers in Linguistics 25. 1-65. https://doi.org/10.11575/PRISM/28976.

Borer, Hagit. 2005. Structuring sense: In name only. Oxford: Oxford University Press.

Cabredo Hofherr, Patricia. 2021. Nominal number morphology. In Patricia Cabredo Hofherr \& Jenny Doetjes (eds.), The Oxford handbook of grammatical number. Oxford: Oxford University Press. https://doi.org/10.109 3/oxfordhb/9780198795858.013.7.

Cardinaletti, Anna \& Giuliana Giusti. 2006. The syntax of quantified phrases and quantitative clitics. In Martin Everaert \& Henk van Riemsdijk (eds.), The Blackwell companion to syntax, vol. 5, 23-93. Oxford: Blackwell. http s://doi.org/10.1002/9780470996591.ch71.

Carlson, Gregory. 2006. The meaningful bounds of incorporation. In Svetlana Vogeleer \& Liliane Tasmowski (eds.), Non-definiteness and plurality, 35-50. Amsterdam: John Benjamins.

Cinque, Guglielmo. 2005. Deriving Greenberg's universal 20 and its exceptions. Linguistic Inquiry 36(3). 315-332. https://doi.org/10.1162/o024389 O54396917.

Clark, Ross. 1975. Mele notes. Auckland University Working Papers in Anthropology, Archaeology, Linguistics, and Maori Studies 40.

Clark, Ross. 1998. A dictionary of the Mele language (Atara Imere), Vanuatu. The Australian National University: Pacific Linguistics. https://doi.org/1 O.15144/PL-C149.

Clark, Ross. 2002. Ifira-Mele. In John Lynch, Malcolm Ross \& Terry Crowley (eds.), The Oceanic languages, 681-693. Routledge.

Corbett, Greville. 200o. Number. Cambridge, UK: Cambridge University Press. Corver, Norbert \& Joost Zwarts. 2006. Prepositional numerals. Lingua 116(6). 811-835. https://doi.org/10.1016/j.lingua.2005.03.008.

Danon, Gabi. 2012. Two structures for numeral-noun constructions. Lingua 122(12). 1282-1307. https://doi.org/10.1016/j.lingua.2012.07.003. 
Dayal, Veneeta. 2011. Pseudo incorporation in Hindi. Natural Language and Linguistic Theory 29. 123-167. https://doi.org/10.1007/s11049-011-91184 .

Dayal, Veneeta. 2015. Incorporation: Morpho-syntactic vs. semantic considerations. In Olga Borik \& Berit Gehrke (eds.), The syntax and semantics of incorporation, syntax and semantics, vol. 40. Leiden: Brill. https://doi.or g/10.1163/9789004291089_0o3.

Donabédian, Anaïd. 1993. Le plureil en arménien moderne. Faits de Langues 2. 179-188. https://doi.org/10.3406/flang.1993.1318.

Enç, Murvet. 1991. Semantics of specificity. Linguistic Inquiry 22-25(1). 1. ww w.jstor.org/stable/4178706.

Farkas, Donka \& Henriëtte de Swart. 2003. The semantics of incorporation. Stanford: CSLI Publications.

Farkas, Donka \& Henriëtte de Swart. 2010. The semantics and pragmatics of plurals. Semantics and Pragmatics 3. 1-54. https://doi.org/10.3765/sp.3 .6 .

Franks, Steven. 1994. Parametric properties of numeral phrases in Slavic. Natural Language and Linguistic Theory 12. 597-674. https://doi.org/10.100 7/BFoog92929.

Franks, Steven. 1995. Parameters of Slavic morphosyntax. Oxford University Press.

Gajewski, Jon. 2002. On analyticity in natural language. Ms., Massachusetts Institute of Technology. https://jon-gajewski.uconn.edu/wp-content/up loads/sites/1784/2016/o8/analytic.pdf.

Giusti, Giuliana. 1997. The categorial status of determiners. In Liliane Haegeman (ed.), The new comparative syntax, 95-123. Longman.

Giusti, Giuliana. 2002. The functional structure of noun phrases: A bare phrase structure approach. In Guglielmo Cinque (ed.), Functional structure in DP and IP, 54-90. Oxford: Oxford University Press.

Göksel, Aslı \& Celia Kerslake. 2005. Turkish: A comprehensive grammar. Routledge.

Görgülü, Emrah. 2011. Plural marking in Turkish: Additive or associative? Working Papers of the Linguistics Circle of the University of Victoria 21. 70-80. https://journals.uvic.ca/index.php/WPLC/article/view/5814.

Görgülü, Emrah. 2012. Semantics of nouns and the specification of number in Turkish. British Columbia: Simon Fraser University dissertation.

Greenberg, Joseph. 1966. Language universals, with special reference to feature hierarchies. The Hague: Mouton. 
Grimm, Scott. 2013. Plurality is distinct from number-neutrality. North East Linguistic Society (NELS) 41.

Hackl, Martin. 2001. Comparative quantifiers. Cambridge, MA: Massachusetts Institute of Technology dissertation.

Harbour, Daniel. 2011. Descriptive and explanatory markedness. Morphology 21. 223-245. https://doi.org/10.1007/s11525-010-9167-o.

Harbour, Daniel. 2014. Paucity, abundance and the theory of number. Language 9o(1). 185-229. https://doi.org/10.1353/lan.2014.0003.

Harbour, Daniel. 2016. Impossible persons. Cambridge, MA: MIT Press.

Heim, Irene. 1991. Artikel und Definitheit. In Arnim von Stechow \& Dieter Wunderlich (eds.), Semantik: ein internationals Handbuch der zeitgenössischen Forschung, 487-535. Berlin: de Gruyter.

von Heusinger, Klaus \& Katlin Kornfilt. 2005. The case of the direct object in Turkish: Semantics, syntax and morphology. Turkic Languages 9. 3-44. http://www.digizeitschriften.de/dms/img/?PID=PPN666048797_ooo9 \%7CLOG_0014.

Hofling, Charles Andrew. 2000. Itzaj Maya grammar. University of Utah Press. Ionin, Tania \& Ora Matushansky. 2006. The composition of complex cardinals. Journal of Semantics 23(4). 315-36o. https://doi.org/10.1093/jos/ff loo6.

Ionin, Tania \& Ora Matushansky. 2018. Cardinals: The syntax and semantics of cardinal-containing expressions. Cambridge, MA: MIT Press.

Ivlieva, Natalia. 2013. Scalar implicatures and the grammar of plurality and disjunction. Cambridge, MA: Massachusetts Institute of Technology dissertation.

Kan, Seda. 2010. Number marking and Turkish noun phrases. ms., University of Massachusetts, Amherst.

Karlsson, Fred. 1982. Finnische Grammatik. Hamburg: Helmut Buske.

Kayne, Richard. 2010. A note on the syntax of numerical bases. In Comparisons and contrasts, 57-72. Oxford: Oxford University Press.

Ketrez, Nihan. 2003. -lar-marked nominals and three types of plurality in Turkish. Chicago Linguistics Society (CLS) 39. 176-193.

Khanjian, Hrayr. 2012. Quantification in Western Armenian. In Edward Keenan \& Denis Paperno (eds.), Handbook of quantifiers in natural language, 84589o. https://doi.org/10.1007/978-94-007-2681-9_16.

Kiparsky, Paul \& Judith Tonhauser. 2012. Semantics of inflection. In Claudia Maienborn, Klaus von Heusinger \& Paul Portner (eds.), Handbook of se- 
mantics, 2070-2097. Berlin: de Gruyter. https://doi.org/10.1515/9783110 589849-002.

Knecht, Laura. 1986. Subject and object in Turkish. Cambridge, MA: Massachusetts Institute of Technology dissertation.

Kornfilt, Jaklin. 1997. Turkish. Routledge.

Krifka, Manfred. 1989. Nominal reference, temporal constitution and quantification in event semantics. In Renate Bartsch, Johan van Benthem \& Peter van Emde Boas (eds.), Semantics and contextual expression. Dordrecht. https://doi.org/10.1515/9783110877335-005.

Krifka, Manfred. 1995. Common nouns: A contrastive analysis of Chinese and English. In Greg Carlson \& Jeffrey Pelletier (eds.), The generic book, 398411. Chicago, IL: Chicago University Press.

Laidig, Wyn D. \& Carol J. Laidig. 199o. Larike pronouns: Duals and trials in a Central Moluccan language. Oceanic Linguistics 29(2). 87-109. https://do i.org/10.2307/3623187.

Landman, Fred. 2011. Count nouns - mass nouns, neat nouns - mess nouns. In Barbara H. Partee, Michael Glanzberg \& Jurgis Škilters (eds.), The Baltic international yearbook of cognition, logic and communication, vol. 6, 1-67. Manhattan, KS: New Prairie Press. https://doi.org/10.4148/biyclc.v6io.15 79 .

Lasersohn, Peter. 1995. Plurality, conjunction, and events. Vol. 55 (Studies in Linguistics and Philosophy). Springer.

Lasersohn, Peter. 2011. Mass nouns and plurals. In Klaus von Heusinger, Claudia Maienborn \& Paul Portner (eds.), Semantics: An international handbook of natural language meaning, vol. 2, 1131-1153. Berlin: de Gruyter.

Lewis, Geoffrey. 1967. Turkish grammar. OUP.

Link, Godehard. 1983. The logical analysis of plural and mass terms: A latticetheoretical approach. In Rainer Bäuerle, Christoph Schwarze \& Arnim von Stechow (eds.), Meaning, use and interpretation of language, 302-323. Berlin: de Gruyter. https://doi.org/10.1515/9783110852820.302.

Longobardi, Giuseppe. 2001. The structure of DPs: Some principles, parameters and problems. In Mark Baltin \& Chris Collins (eds.), The handbook of contemporary syntactic theory, 562-603. Oxford: Blackwell. https://doi.o rg/10.1002/9780470756416.chi8.

Martí, Luisa. 2017. [ \pm Atomic]. Talk presented at the 27th Colloquium in Generative Grammar, Universidad de Alcalá, Spain.

Martí, Luisa. 2020. Inclusive plurals and the theory of number. Linguistic Inquiry 51(1). 37-74. https://doi.org/10.1162/ling_a_oo33o. 
Martí, Luisa. 2022. Number in Imere. In Paolo Acquaviva \& Michael Daniel (eds.), Number in the world's languages: A comparative handbook (Comparative Handbooks in Linguistics (CHL) 5). Berlin: De Gruyter.

Martí, Luisa \& Tania Ionin. 2019. Wide scope indefinites in Russian: An experimental investigation. Glossa: A Journal of General Linguistics 4(1). ht tps://doi.org/10.5334/gjgl.612.

Massam, Diane. 2001. Pseudo incorporation in Niuean. Natural Language and Linguistic Theory 19. 153-197. https://doi.org/10.1023/A:1006465130442. Mayr, Clemens. 2015. Plural definite NPs presuppose multiplicity via embedded exhaustification. Semantics and Linguistic Theory (SALT) 25. 204-224. https://doi.org/10.3765/salt.v25io.3059.

McKay, Graham R. 1978. Pronominal person and number categories in Rembarrnga and Djeebbana. Oceanic Linguistics 17(1). 27-37. https://doi.org /10.2307/3622826.

McKay, Graham R. 1979. Gender and the category unit augmented. Oceanic Linguistics 18(2). 203-210. https://doi.org/10.2307/3622876.

Mithun, Marianne. 1984. The evolution of noun incorporation. Language 6o(4). 847-894. https://doi.org/10.1353/lan.1984.0038.

Mittendorf, Ingo \& Lousie Sadler. 2005. Numerals, nouns and number in Welsh NPs. Conference on Lexical Functional Grammar (LFGO5). 294-312.

Nakanishi, Kimiko \& Satoshi Tomioka. 2004. Japanese plurals are exceptional. Journal of East Asian Linguistics 13. 113-140. https://doi.org/1 o.1023/B:JEAL.0000019058.46668.c1.

Nelson, Diane \& Ida Toivonen. 2000. Counting and the grammar: Case and numerals in Inari Sami. Leeds Working Papers in Linguistics 8. 179-192.

Nevins, Andrew. 2011. Marked targets vs. marked triggers and impoverishment of the dual. Linguistic Inquiry 42(3). 413-444. https://doi.org/10.11 62/LING_a_00052.

Nevskaya, Irina. 2005. Inclusive and exclusive in Turkic languages. In Elena Filimonova (ed.), Clusivity: Typology and case studies of the inclusiveexclusive distinction, 341-358. Amsterdam/Philadelphia: John Benjamins Publishing Company. https://doi.org/10.1075/tsl.63.16nev.

Noyer, Rolf. 1992. Features, positions and affixes in autonomous morphological structure. Cambridge, MA: Massachusetts Institute of Technology dissertation.

Onambélé, Christophe. 2012. Vers une grammaire minimaliste de certains aspects syntaxiques de la langue ewondo. Paris, France: Université Paris 8 dissertation. 
Öztürk, Balkız. 2009. Incorporating agents. Lingua 119(2). 334-358. https://d oi.org/10.1016/j.lingua.2007.10.018.

Renans, Agata, George Tsoulas, Raffaella Folli, Nihan Ketrez, Lyn Tieu, Hanna de Vries \& Jacopo Romoli. 2017. Turkish plural nouns are number-neutral: Experimental data. The 21st Amsterdam Colloquium. 365-374.

Rothstein, Susan. 2010a. Bare noun semantics, kind interpretations and the universal grinder. Bare Nominals and Genericity Conference, Paris.

Rothstein, Susan. 2010b. Counting and the mass-count distinction. Journal of Semantics 27(3). 343. https://doi.org/10.1093/jos/ffqoo7.

Rothstein, Susan. 2011. Counting, measuring and the semantics of classifiers. In Barbara H. Partee, Michael Glanzberg \& Jurǵis Škilters (eds.), The Baltic international yearbook of cognition, logic and communication, vol. 6, 1-42. Manhattan, KS: New Prairie Press. https://doi.org/10.4148/biyclc.v6io.15 82.

Rothstein, Susan. 2017. Semantics for counting and measuring. Cambridge, UK: Cambridge University Press.

Rubino, Carl Ralph Galvez. 1997. A reference grammar of Ilocano. Santa Barbara, CA: University of California, Santa Barbara dissertation.

Sadler, Louisa. 2000. Noun phrase structure in Welsh. In Miriam Butt \& Tracy Holloway King (eds.), Argument realization, 73-110. Stanford: CSLI Publications.

Sağ, Yağmur. 2016. On the semantics of classifiers: A new perspective from an optional classifier language. Turkish. https://ling.auf.net/lingbuzz/oo29 99.

Sağ, Yağmur. 2017. The semantics of Turkish numeral constructions. Sinn und Bedeutung $(\mathrm{SuB})$ 22. 307-324.

Sauerland, Uli. 2003. A new semantics for number. Semantics and Linguistic Theory (SALT) 13. 258-275. https://doi.org/10.3765/salt.v13io.2898.

Sauerland, Uli, Jan Anderssen \& Kazuko Yatsushiro. 2005. The plural is semantically unmarked. In Stefan Kepser \& Marga Reis (eds.), Linguistic evidence, 409-30. de Gruyter.

Schuh, Rusell. 1989. Number and gender in Miya. In Zygmunt Frajzyngier (ed.), Current progress in Chadic linguistics: International symposium on Chadic linguistics, 171-181. Amsterdam: John Benjamins Publishing Company.

Schuh, Rusell. 1998. A grammar of Miya. University of California Press.

Scontras, Greg. 2014. The semantics of measurement. Cambridge, MA: Harvard University dissertation. 
Sebüktekin, Hikmet. 1971. Turkish-English contrastive analysis. The Hague, Paris: Mouton.

Shlonsky, Ur. 2004. The form of semitic noun phrases. Lingua 114(12). 14651526. https://doi.org/10.1016/j.lingua.2003.09.019.

Sigler, Michele. 1997. Specificity and agreement in standard Western Armenian. Cambridge, MA: Massachusetts Institute of Technology dissertation.

Sigler, Michele. 2003. A note on the classifier in Western Armenian: Had. Annual of Armenian Linguistics 22-23. 41-53.

Spector, Benjamin. 2007. Aspects of the pragmatics of plural morphology: On higher-order implicatures. In Uli Sauerland \& Penka Stateva (eds.), Presuppositions and implicatures in compositional semantics. 243-281.

Tompa, József. 1968. Ungarische Grammatik. The Hague: Mouton.

Walter, Micah. 2014. Morphosyntax and semantic type of NPs in Turkish. Haverford, PA: Haverford College BA thesis.

Wilhelm, Andrea. 2008. Bare nouns and number in Dëne Sųiné. Natural Language Semantics 16. 39-68. https://doi.org/10.1007/s11050-007-9024-9.

Williams, Edwin. 1983. Syntactic and semantic categories. Linguistics and Philosophy 6(3). 423-446. http://www.jstor.org/stable/25001136.

Yatsushiro, Kazuko, Uli Sauerland \& Artemis Alexiadou. 2017. The unmarkedness of plural: Crosslinguistic data. Boston University Conference on Language Development (BUCLD) 41. 753-765.

Zweig, Eytan. 2009. Number-neutral bare plurals and the multiplicity implicature. Linguistics and Philosophy 32. 353-407. https://doi.org/10.1007/s 10988-009-9064-3.

Luisa Martí

Department of Linguistics

Queen Mary University of London

Mile End Road

E1 4NS, London, UK

luisa.marti@qmul.ac.uk 